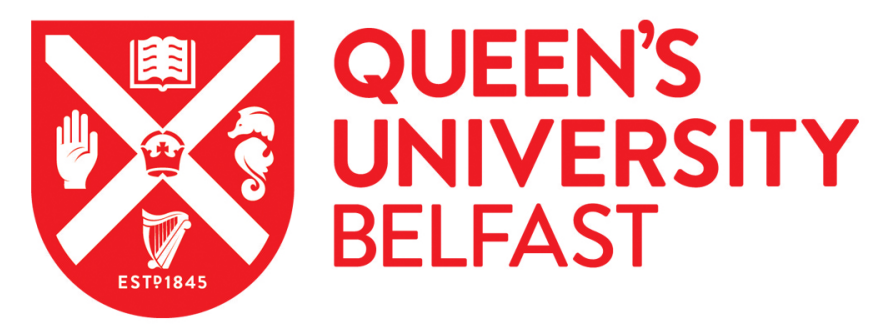

\title{
Prediction of the hydrophobicity of platinum(IV) complexes based on molecular surface properties
}

Zou, J. W., Cui, G. Y., Huang, M., Hu, G. X., \& Jiang, Y. J. (2021). Prediction of the hydrophobicity of platinum(IV) complexes based on molecular surface properties. JOURNAL OF INORGANIC BIOCHEMISTRY, 217, [111373]. https://doi.org/10.1016/j.jinorgbio.2021.111373

Published in:

JOURNAL OF INORGANIC BIOCHEMISTRY

Document Version:

Peer reviewed version

Queen's University Belfast - Research Portal:

Link to publication record in Queen's University Belfast Research Portal

Publisher rights

Copyright 2021 Elsevier.

This manuscript is distributed under a Creative Commons Attribution-NonCommercial-NoDerivs License

(https://creativecommons.org/licenses/by-nc-nd/4.0/), which permits distribution and reproduction for non-commercial purposes, provided the author and source are cited.

\section{General rights}

Copyright for the publications made accessible via the Queen's University Belfast Research Portal is retained by the author(s) and / or other copyright owners and it is a condition of accessing these publications that users recognise and abide by the legal requirements associated with these rights.

Take down policy

The Research Portal is Queen's institutional repository that provides access to Queen's research output. Every effort has been made to ensure that content in the Research Portal does not infringe any person's rights, or applicable UK laws. If you discover content in the Research Portal that you believe breaches copyright or violates any law, please contact openaccess@qub.ac.uk. 


\title{
Prediction of the hydrophobicity of platinum(IV)
}

\section{complexes based on molecular surface properties}

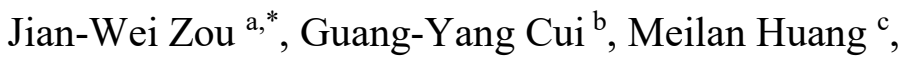 \\ Gui-Xiang $\mathrm{Hu}^{\text {a }}$, Yong-Jun Jiang ${ }^{\text {a }}$
}

${ }^{\text {a }}$ School of Biological and Chemical Engineering, NingboTech University, Ningbo 315100, China

${ }^{\mathrm{b}}$ College of Chemical and Biological Engineering, Zhejiang University, Hangzhou 310058, China

${ }^{c}$ School of Chemistry and Chemical Engineering, Queen's University Belfast, David Keir Building, Stranmillis Road, Belfast BT9 5AG, UK

\section{Corresponding Author}

*E-mail:jwzou@nit.zju.edu.cn. Phone:(+86)574-88130129. Fax:(+86)574-88229516. 
ABSTRACT A quantitative structure-property relationship (QSPR) study was performed for predicting the hydrophobicity of $\mathrm{Pt}(\mathrm{IV})$ complexes. Two four-parameter equations, one based solely on structural descriptors derived from electrostatic potentials (ESPs) on molecular surface, and the other integrated ESP descriptors with molecular surface area $\left(A_{S}\right)$, were firstly constructed. Mechanistic interpretations of the structural descriptors introduced were elucidated in terms of solute-solvent intermolecular interactions. Subsequently, several up-to-date modeling techniques, including support vector machine (SVM), least-squares support vector machine (LSSVM), random forest (RF) and Gaussian process (GP), were utilized to build the nonlinear models. Systematical validations including leave-one-out cross-validation, the validation for test set, as well as a more rigorous Monte Carlo cross-validation were performed to verify the reliability of the constructed models. The predictive performances of the four different nonlinear modeling methods follow the order of LSSVM $\approx \mathrm{GP}>\mathrm{RF}>\mathrm{SVM}$. The pure-ESP-based models are generally inferior to the $A_{S}$-integrated ones. Comparisons with previous results were made.

Keywords: hydrophobic index, electrostatic potential, structural descriptor, QSPR, platinum complex, nonlinear modeling

Abbreviations: ESP, electrostatic potential; GP, Gaussian process; LOO, leave-one-out; LSER, linear solvation energy relationship; LSSVM, least-squares support vector machine; MCCV, Monte Carlo cross-validation; MLR, multiple linear regression; QSPR/QSAR, quantitative structure-property/activity relationship; $\mathrm{R}^{2}$, coefficient of determination; RF, random forest; RMSEE, root mean square error of estimation; RMSCV, root mean square error of cross-validation; RMSEP, root mean square error of prediction; SVM, support vector machine. 


\section{Introduction}

Hydrophobicity, often expressed as the logarithm of the partition coefficient of a compound distributed between immiscible phases of $n$-octanol and water $(\log P)$, is undoubtedly of outstanding importance in the research fields of pharmacological and environmental sciences [1,2]. Experimental determination of $\log P$ is an expensive and labor-intensive task, and sometimes, restricted by lack of solutes with high purity. It is therefore of great significance to seek alternative approaches to estimate accurately the $\log P$ values. So far, a host of approaches and related software tools for this purpose have been developed and summarized in several review papers [3-6]. These approaches can be roughly divided into two categories, substructure and whole-molecule approaches. In the whole-molecule approach, the molecule is treated as an entirety. Structural descriptors are calculated firstly, and then, the quantitative relationship between these structural descriptors and $\log P$ is established with different statistical methods.

Physicochemical properties of chemical substances are usually associated with intermolecular non-covalent interactions. It has been proven to be feasible to predict the physicochemical properties with quantitative structure-property relationship (QSPR) models constructed from characteristics of molecular surface, or more exactly, from structural descriptors based on molecular surface [7-10]. Molecular electrostatic potential (ESP) is a quantum-mechanical quantity with rigorous definition [11]. It has received extensive applications due to the capability of characterizing local or site-specific properties of a molecule [12,13]. Moreover, a group of descriptors based on ESPs (mostly on molecular surface) put forward by Politzer and Murray, have been successfully applied in various QSPR studies [14-20].

Following up these previous advances, we introduced the concept of independent surface ESP and developed a series of new statistically-based descriptors [21-26]. It was indicated that these descriptors are fairly effective for correlating and predicting a variety of solution, liquid phase and binding physicochemical properties that depend upon non-covalent interactions [20]. Especially, this set of descriptors can be well used to describe the quantitative structure-hydrophobicity relationship not only for organic compounds with subtle structural difference $[21,22]$, but also for substituent groups $\left(\pi_{\mathrm{X}}\right)$ and even molecular fragments $\left(f_{\text {oct }}\right)[26]$.

As compared to common organic compounds, metal complexes have quite 
different bonding mode and electronic structures. Obviously, it is usually difficult to predict the physicochemical properties of metal complexes from molecular structures due to computational complexity or sometimes lack of relevant parameters. Thus, it would be beneficial to know whether the structure descriptors derived from ESPs on molecular surface, that are often used for common organic compounds, can also be applied to estimate the physicochemical properties of the metal complexes.

Among metal complexes, $\mathrm{Pt}(\mathrm{II})$ complexes are of great importance and continuing interest in chemistry and pharmaceutical fields [27-29]. The discovery of cisplatin, cis- $\left[\mathrm{PtCl}_{2}\left(\mathrm{NH}_{3}\right)_{2}\right]$, represents a milestone in the history of antitumor agents [27]. Pt(IV) complexes, serving as prodrugs, can be reduced to the corresponding $\mathrm{Pt}(\mathrm{II})$ counterparts upon losing the axial ligands in the hypoxic tumor milieu, and as compared to the latter, they show relative inertness and consequent low systemic toxicity outside the cell [30]. Accordingly, their synthesis, physicochemical properties as well as biological behaviors have also aroused wide attention in recent years [31-33].

Platts and coworkers [34] reported the QSPR models based on exposed surface areas of polar and nonpolar atoms to predict the hydrophobicity of platinum complexes. Similar works have since been published in the literature [35-40]. The quality and reliability of early models are generally low since available experimental data is really limited and the sample size used for modeling is too small. Recently, with the accumulation of experimental data, structural diversity of the complexes has increased, and the reliability of the model has been significantly improved. Some statistical models based on atomic additivity (substructure method) have also been developed to directly calculate the $\log P$ of platinum complexes [38].

In this paper, we report new descriptors derived from ESPs on molecular surface, focusing on the quantitative structure-hydrophobicity relationship of $\operatorname{Pt}(\mathrm{IV})$ complexes. It would provide a new approach for predicting the physicochemical properties of metal complexes.

\section{Computational details}

All quantum chemical calculations were performed with the Gaussian 09 software package [41]. Firstly, the initial geometry of each Pt(IV) complex was optimized with the hybrid functional B3LYP method using mixed basis set (SDD effective core potential for Pt and 6-31+G(d,p) for other atoms). In previous comparative tests for Pt 
complexes, this level of theory was proven to reproduce well the molecular structures and NMR spectra [42]. Based on the optimized geometries, electronic densities and ESPs were calculated with grid method. The grid control option was set to "cube = 100 ", and therefore, about $100^{3}$ values of electronic density and ESP were computed for each molecule. Subsequently, the points on molecular surface (the outer isodensity envelope of $\rho(\mathrm{r})=0.001$ a.u.) as well as their ESP values were extracted. Then, a total of 33 descriptors derived from these ESPs, were calculated by using an in-house program. Some of these structural descriptors, e.g. spatial and surface extrema of the ESPs, average positive or negative ESPs, $\sigma_{\text {tot }}^{2}$ and $v$ (vide infra), were suggested by Politzer et al. [19,20], and most were developed or modified in our group [21-26].

Correlations of the descriptors with the hydrophobicity index were established with multiple linear regression (MLR) analysis. Several up-to-date modeling techniques including support vector machine (SVM) [43], least-squares support vector machine (LSSVM) [44], random forest (RF) [45] and Gaussian process (GP) [46] were also adopted with expect to yield better predictive models.

The stability and predictive power of these models were verified by leave-one-out (LOO) and rigorous Monte Carlo cross-validation (MCCV) [47]. In MCCV, the whole data set was split randomly into a training set and a test set in 3:1 ratio and an external $R^{2}\left(R_{\text {ext }}^{2}\right)$ was used as the evaluation criterion. It was calculated from the following formula [48].

$$
R_{\text {ext }}^{2}=1-\frac{\sum_{i=1}^{n_{\text {test }}}\left(y_{i}^{\text {expl }}-y_{i}^{\text {pred }}\right)^{2}}{\sum_{i=1}^{n_{\text {test }}}\left(y_{i}^{\text {expl }}-\bar{y}_{t r}\right)^{2}}
$$

where $\bar{y}_{t r}$ is the averaged value of the response variables for the training set, $y_{i}^{\text {expl }}$ and $y_{i}^{\text {pred }}$ are experimental and predicted values of the test set, respectively. Each cross-validation calculation yielded a $R_{\text {ext }}^{2}$ value, and the process was repeated $2^{16}=65536$ times. From these results the cumulative distribution function of $R_{\text {ext }}^{2}$ is estimated by:

$$
P_{\text {cum }}\left(R_{\text {ext }}^{2}<x\right)=\int_{-\infty}^{x} p\left(R_{\text {ext }}^{2}\right) d x
$$

where $p\left(R_{\text {ext }}^{2}\right)$ is the probability density of $R_{\text {ext }}^{2}$. The median $R_{\text {ext }}^{2}$ corresponds to an $x$ value of $P_{\text {cum }}=0.5$, which represents the demarcation dividing the whole sampled $R_{\text {ext }}^{2}$ equally. The integral $R_{\text {ext }}^{2}$ is defined by the following formula.

$$
\text { integral } R_{\text {ext }}^{2}=\int_{0}^{1}\left[1-P_{\text {cum }}\left(R_{\text {ext }}^{2}<x\right)\right] d x
$$


It describes the distribution of the entire $R_{\text {ext }}^{2}$ probability density, and its value lies between 0 and 1 . The peak $R_{\text {ext }}^{2}$ is the peak position of $R_{\text {ext }}^{2}$ probability density and indicates the most probable location of sampled $R_{\text {ext }}^{2}$. The peak, median and integral $R_{\text {ext }}^{2}$ values were served as the measures of model quality.

\section{Results and Discussion}

\subsection{The QSPR models for $\log k_{0}^{\prime}$}

The data set was taken from previous publication [36]. The hydrophobic indexes expressed as $\log k_{0}^{\prime}$ ( $k_{0}^{\prime}$ is the HPLC capacity factor extrapolated to $100 \%$ water) for $53 \mathrm{Pt}(\mathrm{IV})$ complexes are collected in Table 1. The original data set was first split into a training set and test set in the ratio of $3: 1$. The 13 complexes in the test set were randomly selected as those numbered as $4 \mathrm{n}$ and marked with asterisks in Table 1 .

By using stepwise linear regression and selecting pure ESP-based structural descriptors as independent variables, a four-parameter QSPR model (Eq. (4)) was firstly established for the training set as follow:

$$
\begin{gathered}
\log k_{0}^{\prime}=0.0695 * N_{s, \text { ind }}^{+}-0.0393 * 2 V_{s, \text { ind }}^{+}-18.9985 * \overline{V_{s, \text { ind }}^{0,+}}-14.9856 * v_{\text {ind }}+3.0721 \\
N=40, R^{2}=0.87, R M S E E=0.69, R_{C V}^{2}=0.81, R M S C V=0.82, R_{\text {Pred }}^{2}=0.77, R M S E P=0.83
\end{gathered}
$$

where and throughout this paper, $N$ is the number of data points submitted for regression; $R^{2}$ and $R M S E E$ are fitting coefficient of determination and root mean square error of estimation; $R_{C V}^{2}$ and $R M S C V$ are LOO cross-validation coefficient and root mean square error of LOO cross-validation; $R_{\text {Pred }}^{2}$ and $R M S E P$ are predictive coefficient of determination and root mean square error of prediction.

Considering the fact that the hydrophobicity of a compound is generally associated with molecular size, we also incorporated molecular volume and molecular surface area $\left(A_{S}\right)$ in the MLR analysis and obtained a similar four-parameter model (Eq. (5)).

$$
\begin{gathered}
\log k_{0}^{\prime}=0.0227 * A_{s}-9.6066 * v-20.5437 * \overline{V_{s, \text { ind }}^{0,+}}-0.0653 * N_{s, \text { ind }}^{-}+2.7300 \\
N=40, R^{2}=0.89, R M S E E=0.64, R_{C V}^{2}=0.85, R M S C V=0.73, R_{\text {Pred }}^{2}=0.87, R M S E P=0.63
\end{gathered}
$$

It can be seen that, as compared to Eq. 4, Eq. 5 shows larger $R^{2}, R_{C V}^{2}$ and $R_{P r e d}^{2}$ values, and smaller RMSEE, RMSCV and RMSEP values, which means that the 
$A s$-integrated QSPR model has better fitting and predictive power. Nevertheless, the difference in statistical quality between the two models is not quite large, and both would be taken into account in subsequent discussion. Using Eqs. 4 and 5, we predicted the hydrophobicity for all complexes. The results are tabulated in Table S1 as supporting information. The plots of predicted versus experimental $\log k_{0}^{\prime}$ values for both the training set and the test set shows good fitting (Fig. 1).

As more than one variable are introduced in the models, it is necessary to examine the stability of the regression equations. Upon investigating the collinearity of variables in Eqs. 4 and 5, we obtained the variance inflation factor (VIF) for each descriptor (Table S2). According to statistics principle [49], a value of 1.0 is indicative of no correlation, while a value less than 10.0 is statistically acceptable. It is shown that all of the VIF values are less than 2.0, indicating that the stability of the QSPR models constructed are highly satisfactory.

\subsection{Mechanistic interpretation of the descriptors involved}

$A_{S}$ reflects the size of a molecule and has been demonstrated to be an important descriptor in determining partition coefficients of organic compounds. It is presented in Eq. 5 and positively correlated with $\log k_{0}^{\prime}$, which indicates that the $\operatorname{Pt}(\mathrm{IV})$ complex with larger size is more liable to distribute into nonpolar phase. According to the concept of linear solvation energy relationship (LSER) [50], $A_{S}$ (or molecular volume) can be viewed as a cavity term, which is a measure of the energy needed to overcome the cohesive forces in order to form a cavity for the solute, and the larger molecules would tend to be excluded from the more polar solvent water.

All other structural descriptors included in Eqs. 4 and 5 are derived statistically from the ESPs on molecular surface. Five of them are associated with the independent ESPs, and among which $\overline{V_{s, \text { ind }}^{0,+}}$ appeared for the first time in our QSPR/QSAR studies. The so-called independent ESPs refer to the statistically calculated ESPs of those points on molecular surface with pairwise distance of above $0.21 \mathrm{~nm}$. The cutoff value $0.21 \mathrm{~nm}$ is the arithmetic mean value between the van der Waals radius of a water molecule $(0.14 \mathrm{~nm})$ and the diameter of the water molecule $(0.28 \mathrm{~nm})$ [21].

$\Sigma V_{s, \text { ind }}^{+}$is the sum of the independent positive ESPs. The summation starts from the most positive ESP on molecular surface $\left(V_{s, \max }\right)$, and the corresponding position of $V_{s, \max }$ is viewed as the first independent point. Then the next $V_{s, \max }$ is considered, and 
it is added in the summation only if its distance from the former independent point is larger than $0.21 \mathrm{~nm}$. This operation is repeated until all of the independent points with positive ESPs are included. This descriptor also appeared in previous QSPR modeling for $\log P$ of halogenated methylphenyl ethers [51]. As $2 V_{s, \text { ind }}^{+}$reflects nonspecific intermolecular interactions, it is presented in Eq. 4 and negatively correlated with $\log k_{0}^{\prime}$, indicating that the Pt(IV) complexes with larger positive ESPs tend to interact with water and show lower lipophilicity.

$N_{S, \text { ind }}^{+}$is the number of independent points of positive ESPs on molecular surface. It is the first variable introduced in the model (Eq. 4) upon stepwise regression analysis and can explain about $75 \%$ of the variance of experimental $\log k_{0}^{\prime}$ value. As compared to $2 V_{s, \text { ind }}^{+}, N_{s, \text { ind }}^{+}$represents opposite contribution to the lipophilicity, implying that the complexes distributing with more small positive surface ESPs would be favorable for partition into organic phase (vide infra).

$N_{s, \text { ind }}^{-}$is the number of independent negative ESPs on molecular surface counting from the most negative ESPs. This term contributes negatively to the lipophilicity, which means that the Pt(IV) complex with more negative ESP region also tends to partition into water phase. This makes sense since water is a typical amphiphilic polar molecule (both a good electron donor and a good electron acceptor), and the existence of a large ESP region in the compound, whether positive or negative, is in favor of its interacting with water molecule.

The hydrophobicity and hydrophilicity of a molecule is closely related to the uniformity of ESP distribution on molecular surface [16,18,52]. v, defined as Eq. 6, is a descriptors reflecting uniformity of distribution of $\operatorname{ESPs}\left(\bar{V}_{s}, \overline{V_{s}^{-}}\right.$and $\overline{V_{S}^{+}}$are the average values of surface ESPs, positive and negative surface ESPs, respectively). $v$ is an indicator of the degree of balance between the positive and negative surface potentials, and it reaches a maximum of 0.25 when $\sigma_{+}^{2}=\sigma_{-}^{2} \cdot \sigma_{\text {tot }}^{2}$ is generally viewed as a measure of electrostatic interaction tendency. Compared to $\Pi$, another similar descriptor, it emphasizes the contribution of the extremum and is more sensitive to the variation of the surface ESPs [19,20]. In fact, $\Pi$ and $\sigma_{\text {tot }}^{2}$ have been frequently introduced in previous QSPR models [16,26]. In this work, $v$ and $v_{\text {ind }}$ (balance parameter for the independent ESPs) are found to be statistically significant and give negative contribution to $\log k_{0}^{\prime}$, manifesting that the distribution uniformity of ESPs play important role in the hydrophobicity of $\mathrm{Pt}(\mathrm{IV})$ complex. The $\mathrm{Pt}(\mathrm{IV})$ 
complex with more balanced positive and negative surface ESPs distribution are favorable to enhance the lipophilicity.

$$
\begin{aligned}
& v=\frac{\sigma_{+}^{2} \cdot \sigma_{-}^{2}}{\left(\sigma_{\text {tot }}^{2}\right)^{2}} \\
& \sigma_{\text {tot }}^{2}=\sigma_{+}^{2}+\sigma_{-}^{2}=\frac{1}{m} \sum_{i=1}^{m}\left|V^{+}\left(r_{i}\right)-\overline{V_{s}^{+}}\right|^{2}+\frac{1}{n} \sum_{i=1}^{n}\left|V^{-}\left(r_{i}\right)-\overline{V_{s}^{-}}\right|^{2}
\end{aligned}
$$

As mentioned above, the presence of large positive or negative ESPs on the molecular surface is in favor of interacting with water molecule, and therefore detrimental for the lipophilicity. On the contrary, the contour surface of a typical hydrophobic molecule or fragment (e.g. alkyl group) is usually distributed with small and uniform positive ESPs [16,18,52]. With this in mind, we constructed a group of new descriptors based on statistical calculations starting from the surface ESPs closest to zero, and one of them, $\Sigma V_{s, i n d}^{0,+}$, has been utilized to predict the complexation of structurally diverse compounds with $\beta$-cyclodextrin [23]. In the present work, another descriptor of this type, $\overline{V_{s, i n d}^{0,+}}$, has been found to be statistically significant and was introduced in both models. $\overline{V_{s, i n d}^{0,+}}$ is the average of independent positive ESPs on molecular surface ranging from 0 to 0.01 a.u.. It makes a negative contribution to $\log k_{0}^{\prime}$, meaning that the smaller the absolute value of these tiny positive ESPs, the more favorable it is for lipophilicity. This is consistent with aforementioned analysis.

\subsection{Nonlinear models}

As shown above, the linear models provide satisfactory predictive power and good interpretability. Nevertheless, non-linear models usually give better results. Accordingly, we use several up-to-date non-linear statistical methods, including SVM, LSSVM, RF and GP to deal with the present data set. The input parameters are the structure descriptors introduced in Eqs. 4 and 5. The statistic results of the nonlinear models for both the training set and the test set are displayed in Table 2. For the purpose of comparison, the corresponding values of linear models are also listed. The parameters optimized during the course of nonlinear modeling are summarized in Table S3.

SVM is a machine learning algorithm developed by Vapnik et al. in the framework of the statistical learning theory [43]. It is especially suitable for dealing with 
small-sample, high-dimensional and strong collinear problems due to adopting structural risk minimization (SRM) instead of empirical risk minimization (ERM). LSSVM is developed on the basis of traditional SVM. It introduces a least squares linear system into support vectors, transforms inequality constraints into equality constraints, and converts solving quadratic programming problems into solving linear equations. As a result, the insensitive loss function is avoided, and the computational efficiency is greatly improved [44].

It can be seen from the statistical results given in Table 2 , for the training set, the fitting ability and predictive power of SVM and LSSVM have been improved as compared with the linear MLR models (larger $R^{2}$ and $R_{C V}^{2}$, and smaller RMSEE and RMSCV values), whether the pure ESP descriptor set or the $A_{S}$-integrated one was adopted. For the test set, however, the performances of SVM are unusually poor, the $R_{\text {Pred }}^{2}$ values are not larger than 0.70, and the RMSEP values exceed 0.90. Relatively, LSSVM yields significantly better predictive performance than the traditional SVM as well as MLR, as reflected by the statistical results in Table 2 (all of the coefficients of determination, $R^{2}, R_{C V}^{2}$ and $R_{\text {Pred }}^{2}$, are larger than 0.85, and the RMSEP values drop to ca. 0.6 , regardless of the descriptor set used).

Random forest is a flexible, easy to use machine learning algorithm [45]. This type of algorithm helps to enhance the ways that technologies analyze complex data. It is capable of performing both regression and classification tasks with the use of multiple decision trees and a bagging technique. It is necessary to adjust the parameters in the construction of the decision tree to get the final model with the best parameters. In the present work, two adjustable parameters, number of trees $\left(n_{\text {tree }}\right)$ and size of descriptor subset ( $\left.m_{\text {tree }}\right)$, were optimized using grid-searching method. The optimum $n_{\text {tree }}$ and $m_{\text {tree }}$ (see Table S3) were used to construct the final RF model.

As can be seen from the data in Table 2, the $R^{2}$ values of RF models based on the two different descriptor sets are 0.91 and 0.89 , respectively, and the RMSEE values are 0.58 and 0.64 , respectively, which means that the RF models have relatively good fitting ability. However, from the information reflected by other four statistical quantities, $R_{C V}^{2}, R M S C V, R_{P r e d}^{2}$, and $R M S E P$, the predictive performance of the RF models are relatively poor. 
Gaussian process (GP) is a new type of machine learning algorithm developed on the basis of Bayesian framework and has attracted wide interest of researchers in related fields in recent years [53,54]. It has several advantages over the other nonlinear modeling methods, such as no function constraints, being capable of dealing with linear/nonlinear hybrid problems, automatic determination of the model parameters, and probabilistic significance of the output results. Moreover, the GP method can evaluate the validity and confidence of the prediction results [46].

Recently, we applied this method to construct successfully predictive models of the complexation of structurally diverse compounds with $\beta$-cyclodextrin [23], the bioconcentration factor of nonionic compounds [24], and the minimum alveolar concentration of anesthetic agents [25]. In the current study, we use the general covariance function as the kernel function, which consists of a constant term, a linear term, a square exponential term, and a noise term. The corresponding hyperparameters $\theta_{0}$ (constant term), $\theta_{1}$ (linear term), $\theta_{2}$ (square exponential term), and $\sigma_{v}^{2}$ (noise term) are optimized by conjugate gradient method and displayed in Table S3.

For the training set, the $R^{2}$ values given by GP modeling are 0.94 (Pure ESP-based) and 0.92 ( $A_{S}$-integrated), and the RMSEE values are 0.46 and 0.53 , respectively. The former yields the best fitting ability among all of the models. The performances of GP models, however, are not as excellent as one might expected, from the statistical results of LOO-CV as well as those for the test set. The $R_{C V}^{2}$, $R M S C V, R_{P r e d}^{2}$ and RMSEP values of the As-integrated GP models are almost the same as those of the linear model. This means that the linear components are predominant in the GP modeling, which is supported by the optimized hyperparameters $\theta_{0}, \theta_{1}$ and $\theta_{2}\left(\theta_{0}, \theta_{1}>\theta_{2}\right)$.

Additionally, one of the advantages of the GP method over the other nonlinear modeling techniques lies in that the importance of different descriptors can be measured by the length scales $r_{i}$. Each $r_{i}$ is associated with an input and characterizes the distance in the $i$ th direction over which output is expected to vary significantly. A small $r_{i}$ value corresponds to a relatively important descriptor, whereas a large $r_{i}$ value means that the variation of the corresponding descriptor does not influence the 
property very much. It has been shown that all of the $r_{i}$ values (see Table S4) are less than 3, which means that all the descriptors in Eqs. 4 and 5 are significant for the hydrophobicity of $\mathrm{Pt}(\mathrm{IV})$ complexes. Relatively, $2 V_{s, \text { ind }}^{+}$and the balance parameter $v$ give more important contributions.

Comparing the data listed in Table 2, it is not difficult to infer that the predictive performances of the four different nonlinear modeling methods follow the order of $\mathrm{LSSVM} \approx \mathrm{GP}>\mathrm{RF}>\mathrm{SVM}$. As for comparison between the pure-ESP-based models and the $A_{S}$-integrated ones, the former is in general inferior to the latter. The predicted $\log k_{0}^{\prime}$ values by the LSSVM and GP models are displayed in Table S2. The plots of predicted versus experimental results are illustrated in Fig. 1, from which the fitting and predictive power of these models can be visually compared.

\subsection{Monte Carlo cross-validation tests}

As stated above, the samples in the test set (13 complexes) are randomly selected. Nevertheless, such selection is featured of inherent arbitrariness, and the validation using one single test set is undoubtedly deficient from the point of statistics. In order to systemically test the predictive power of the QSPR models, we used MCCV method with up to $2^{16}=65536$ samplings to perform rigorous validations. Table 2 lists the peak, median and integral $R_{\text {ext }}^{2}$ values. For the pure-ESP-based linear model, they are $0.88,0.82$ and 0.79 , respectively, while for the $A s$-integrated linear model, these three values are $0.90,0.86$ and 0.83 , respectively. Except the integral $R_{\text {ext }}^{2}$ values of the former, they are all larger than 0.80 , demonstrating that both linear models have considerably good stability and predictive power. As for the four nonlinear modeling methods, the MCCV results reveal that their predictive performances follow the same order as the results of the single test set. The LSSVM and GP models are slightly better than the corresponding linear model, and the SVM and RF models are significantly worse.

\subsection{Comparison with previous results}

There have been several reports in the literature about the prediction of the lipophilicity of platinum complexes. However, due to the difference in complex sets adopted, and in some cases, $\mathrm{Pt}(\mathrm{IV})$ complexes have been mixed with $\mathrm{Pt}(\mathrm{II})$ complexes 
together for modeling, direct comparison is often difficult.

Ermondi et al. [36] performed a modeling study with the molecular-interactionfields (MIF) based method for the same data set. They used four types of probes and a total of 92 Volsurf descriptors, and obtained the statistical results as follows: $R^{2}(\mathrm{LOO})=0.87, R^{2}(3$ - and 4 -fold $)=0.85$. For comparison, we have done a similar calculation with partial least squares (PLS) method using all 33 ESP-based descriptors plus $A s$, resulting in $R^{2}(\mathrm{LOO})=0.85, R^{2}(3$-fold $)=0.83$ and $R^{2}$ (4-fold $)=0.82$. The statistical quality of our model is roughly equivalent to that of MIF-based one.

Tetko et al. [38] used fragment-based and whole-molecule methods to develop several models for predicting the lipophilicity of platinum complexes. Particularly, they provided a website for the public to predict the $\log P$ of new Pt complexes. In that work, some models only for the Pt(IV) complexes were reported. In order to make a proper comparison, and meanwhile, to test further the applicability of the ESP-derived descriptors, we performed a QSPR treatment, following the same workflow, for all $122 \mathrm{Pt}(\mathrm{IV})$ complexes reported by Tetko et al. (51 of them are duplicates of the complexes considered in this work, see supporting information). Using the same training set of 87 complexes as Tetko et al. adopted, we obtained a four-parameter model similar to Eq. 5 as follows:

$$
\begin{aligned}
& \log P=0.0139 * A_{s}+0.0673 * V_{s, \max }-0.0158 * N_{s, \text { ind }}^{-}-0.0109 * D_{s, \text { extrm }}-3.6208 \\
& N=87, R^{2}=0.74, R M S E E=0.73, R_{C V}^{2}(5 \text {-fold })=0.71, R M S C V(5 \text {-fold })=0.75
\end{aligned}
$$

Eq. 7 is evidently inferior to Eq. 5, and there is a certain gap between the results and what we expected. Furthermore, two nonlinear modeling methods that performed well in prior work, LSSVM and GP, were used to deal with the data set, but no significantly improvement was found. For the test set consisting of the remaining 35 complexes, this linear model gives $R_{\text {pred }}^{2}=0.59$ and $R M S E P=0.84$.

This result certainly cannot be compared with the best result of Tetko et al. (the cross-validated RMSE values of the associative neural network modeling were 0.36 and 0.66 respectively for the training set and the test set). Nevertheless, it is still acceptable when compared with their MLR results $\left(R_{C V}^{2}(5\right.$-fold $)=0.3-0.78$ and $\operatorname{RMSCV}(5$-fold $)=0.72-1.28$ for the combined set $\mathrm{Pt}(\mathrm{II})$ and $\mathrm{Pt}(\mathrm{IV})$, no results found for 
$\mathrm{Pt}(\mathrm{IV})$ alone), especially considering the good interpretability of the descriptors.

One of main reasons for the unsuccess of the models established for the $53 \mathrm{Pt}(\mathrm{IV})$ complexes to extend to a larger data set is that the 33 descriptors derived from ESPs on molecular surface provide relatively limited information. At present, there are still some deficiencies in QSPR modeling of complex compounds and in QSAR modeling. New descriptors of this type have been developing in our laboratory to extend their applicability.

\section{Summary and Conclusions}

Metal complexes exhibit quite different bonding mode and electronic structure from common organic compounds. It is usually difficult to predict the physicochemical properties of metal complexes from molecular structures due to computational complexity or the lack of relevant parameters. The present paper was aimed at answering the question whether the physicochemical properties of the metal complexes can be predicted regardless of their internal bonding mode and base on molecular surface properties that are often used for common organic compounds. For this purpose, quantitative structure-hydrophobicity relationship for a group of $\operatorname{Pt}(\mathrm{IV})$ complexes was investigated by using the structure descriptors derived from electrostatic potentials (ESPs) on molecular surface.

A four-parameter equation with pure-ESP based descriptors was firstly constructed for the training set consists of $40 \mathrm{Pt}(\mathrm{IV})$ complexes. Incorporation of an additional descriptor reflecting molecular size $\left(A_{S}\right)$ in the modeling resulted in a similar four-parameter equation. A collinearity diagnosis of variables revealed that the VIF values of all descriptors are less than 2.0, demonstrating the robustness of the models. Both models were further validated by rigorous MCCV calculations and showed good stability and predictive power.

Mechanistic interpretations of the structural descriptors introduced were elucidated from the point of view of solute-solvent intermolecular interactions. Especially, $\overline{V_{s, i n d}^{0,+}}$ derived from statistical calculations of the independent surface ESPs ranging from 0 to 0.01 a.u., appeared for the first time in our QSPR/QSAR studies.

Four up-to-date modeling techniques, including SVM, LSSVM, RF and GP, were utilized to build the nonlinear models. The predictive performances of GP and 
LSSVM modeling are satisfactory, as reflected by the statistical results in Table 2. The SVM and RF methods represent poor performance, even worse than the MLR method.

Finally, comparisons with previous predictive models in the literature were made. The results show that the statistical quality of our model constructed with only a few structural descriptors in relation to molecular surface properties is roughly comparable to that of the MIF-based model for the same data set.

\section{Acknowledgements}

The authors are grateful to the Natural Science Foundation of China (Project No. 21272211) and the Program of Science and Technology of Ningbo, China (2019C10083) for financial support.

\section{Declaration of competing interest}

The authors have no conflicts of interest.

\section{Appendix A. Supplementary data}

Supplementary data associated with this article can be found online at doi: https://doi.org/10.1016/j.jinorgbio.****.

\section{References}

[1] A. Sarkar, G.E. Kellogg, Curr. Top. Med. Chem. 10 (2010) 67-83.

[2] A.J. Leo, C. Hansch, Perspect. Drug Discov. Design 17 (1999) 1-25.

[3] A.J. Leo, Chem. Rev. 93 (1993) 1281-1306.

[4] R. Mannhold, G.I. Poda, C. Ostermann, I.V. Tetko, J. Pharm. Sci. 98 (2009) 861-893.

[5] D.E. Smith, A.D.J. Haymet, Rev. Comput. Chem. 19 (2003) 43-77.

[6] R. Mannhold, H. van de Waterbeemd, J. Comput.-Aid. Mol. Design 15 (2001) 337-354.

[7] T. Clark, J. Mol. Graph. Model. 22 (2004) 519-525.

[8] J. Polanski, B. Walczak, Comput. Chem. 24 (2000) 615-625.

[9] L. Michielan, M. Bacilieri, C. Kaseda, S. Moro, Biorg. Med. Chem. 16 (2008) 5733-5742.

[10] J. Kelder, P.D.J. Grootenhuis, D.M. Bayada, L.P.C. Delbressine, J.P. Ploemen, Pharm. Res. 16 (1999) 1514-1519.

[11] J.S. Murray, P. Politzer, Wiley Interdisc. Rev. Comput. Mol. Sci. 1 (2011) 153-163.

[12] C.H. Suresh, S.R. Gadre, J. Phys. Chem. A 111 (2007) 710-714.

[13] J.W. Zou, Y.J. Jiang, M. Guo, G.X. Hu, B. Zhang, H.C. Liu, Q.S. Yu, Chem. Eur. J. 11 (2005) 
740-751.

[14] O. Lamarche, J.A. Platts, A. Hersey, J. Chem. Inf. Comput. Sci. 44 (2004) 848-855.

[15] J.S. Murray, F. Abu-Awwad, P. Politzer, J. Phys. Chem. A 103 (1999) 1853-1856.

[16] M. Haeberlein, T. Brinck, J. Chem. Soc. Perkin Trans. 2 (1997) 289-294.

[17] J.S. Murray, P.G. Seybold, R. Battino, P. Politzer, J. Mol. Model. 26 (2020) 244.

[18] Q.S. Du, G.A. Arteca, J. Comput.-Aid. Mol. Design 10 (1996) 133-144.

[19] F.A. Bulat, A. Toro-Labbe, T. Brinck, J.S. Murray, P. Politzer, J. Mol. Model. 16 (2010) 1679-1691.

[20] J.S. Murray, P. Politzer, Wiley Interdisc. Rev. Comput. Mol. Sci. 7 (2017) e13260.

[21] J.W. Zou, W.N. Zhao, Z.C. Shang, M.L. Huang, M. Guo, Q.S. Yu, J. Phys. Chem. A 106 (2002) $11550-11557$.

[22] H.-Y. Xu, J.-W. Zou, G.-X. Hu, W. Wang, Chemosphere 80 (2010) 665-670.

[23] P. Sang, J.-W. Zou, D.-M. Dai, G.-X. Hu, Y.-J. Jiang, Chemo. Intel. Lab. Syst. 127 (2013) 166-176.

[24] P. Sang, J.-W. Zou, P. Zhou, L. Xu, Chemosphere 83 (2011) 1045-1052.

[25] P. Sang, J.-W. Zou, Y.-L. Yu, M.-L. Huang, Chemo. Intel. Lab. Syst. 112 (2012) 8-16.

[26] J.-W. Zou, M. Huang, J.-X. Huang, G.-X. Hu, Y.-J. Jiang, J. Mol. Graph. Model. 64 (2016) $110-120$

[27] F. Trudu, F. Amato, P. Vanhara, T. Pivetta, E.M. Pena-Mendez, J. Havel, J. Appl. Biomed. 13 (2015) 79-103.

[28] S. Dasari, P.B. Tchounwou, Eur. J. Pharmacol. 740 (2014) 364-378.

[29] T. Boulikas, M. Vougiouka, Oncol. Rep. 10 (2003) 1663-1682.

[30] Y. Shi, S.-A. Liu, D.J. Kerwood, J. Goodisman, J.C. Dabrowiak, J. Inorg. Biochem. 107 (2012) 6-14.

[31] M.D. Hall, T.W. Hambley, Coord. Chem. Rev. 232 (2002) 49-67.

[32] A.S. Kritchenkov, Y.M. Stanishevskii, Y.A. Skorik, Pharm. Chem. J. 53 (2019) 6-14.

[33] Z. Deng, N. Wang, Y. Liu, Z. Xu, Z. Wang, T.-C. Lau, G. Zhu, J. Am. Chem. Soc. 142 (2020) 7803-7812.

[34] J.A. Platts, D.E. Hibbs, T.W. Hambley, M.D. Hall, J. Med. Chem. 44 (2001) 472-474.

[35] A.A. Toropov, A.P. Toropova, Chem. Phys. Lett. 701 (2018) 137-146.

[36] G. Ermondi, G. Caron, M. Ravera, E. Gabano, S. Bianco, J.A. Platts, D. Osella, Dalton Trans. 42 (2013) 3482-3489.

[37] S.P. Oldfield, M.D. Hall, J.A. Platts, J. Med. Chem. 50 (2007) 5227-5237.

[38] I.V. Tetko, H.P. Varbanov, M. Galanski, M. Talmaciu, J.A. Platts, M. Ravera, E. Gabano, J. Inorg. Biochem. 156 (2016) 1-13.

[39] G. Caron, M. Ravera, G. Ermondi, Pharm. Res. 28 (2011) 640-646.

[40] J.A. Platts, G. Ermondi, G. Caron, M. Ravera, E. Gabano, L. Gaviglio, G. Pelosi, D. Osella, J. Biol. Inorg. Chem. 16 (2011) 361-372.

[41] M.J. Frisch et al., Gaussian 09, Revision A.1, Gaussian Inc., Wallingford, CT, 2009.

[42] H.W. Gao, X.J. Wei, X.T. Liu, T.X. Yan, J. Phys. Chem. B 114 (2010) 4056-4062. 
[43] R.G. Brereton, G.R. Lloyd, Analyst 135 (2010) 230-267.

[44] R.P. Cogdill, P. Dardenne, J. Near Infrared Spectrosc. 12 (2004) 93-100.

[45] L. Breiman, Machine Learning 45 (2001) 5-32.

[46] M. Seeger, Int. J. Neural Syst. 14 (2004) 69-106.

[47] Q.S. Xu, Y.Z. Liang, Chemo. Intel. Lab. Syst. 56 (2001) 1-11.

[48] V. Consonni, D. Ballabio, R. Todeschini, J. Chem. Inf. Model. 49 (2009) 1669-1678.

[49] D.A. Belesley, E. Kuh, R.E. Welsh, Regression Diagnostics, Wiley, New York, United States, 1990.

[50] M.J. Kamlet, R.M. Doherty, M.H. Abraham, Y. Marcus, R.W. Taft, J. Phys. Chem. 92 (1988) 5244-5255.

[51] H.-Y. Xu, J.-Y. Zhang, J.-W. Zou, X.-S. Chen, J. Mol. Graph. Model. 26 (2008) 1076-1081.

[52] Q.S. Du, G.A. Arteca, P.G. Mezey, J. Comput.-Aid. Mol. Design 11 (1997) 503-515.

[53] O. Obrezanova, G. Csanyi, J.M.R. Gola, M.D. Segall, J. Chem. Inf. Model. 47 (2007) 1847-1857.

[54] P. Zhou, X. Chen, Y. Wu, Z. Shang, Amino Acids 38 (2010) 199-212. 


\title{
Prediction of the hydrophobicity of platinum(IV)
}

\section{complexes based on molecular surface properties}

\author{
Jian-Wei Zou ${ }^{\text {a, }}$, Guang-Yang Cui ${ }^{\mathrm{b}}$, Meilan Huang ${ }^{\mathrm{c}}$, \\ Gui-Xiang $\mathrm{Hu}^{\text {a }}$, Yong-Jun Jiang ${ }^{\text {a }}$
}

${ }^{a}$ School of Biological and Chemical Engineering, NingboTech University, Ningbo 315100, China

${ }^{\mathrm{b}}$ College of Chemical and Biological Engineering, Zhejiang University, Hangzhou 310058, China

${ }^{c}$ School of Chemistry and Chemical Engineering, Queen's University Belfast, David Keir Building, Stranmillis Road, Belfast BT9 5AG, UK

\section{Corresponding Author}

*E-mail:jwzou@nit.zju.edu.cn. Phone:(+86)574-88130129. Fax:(+86)574-88229516. 
ABSTRACT A quantitative structure-property relationship (QSPR) study was performed for predicting the hydrophobicity of $\mathrm{Pt}(\mathrm{IV})$ complexes. Two four-parameter equations, one based solely on structural descriptors derived from electrostatic potentials (ESPs) on molecular surface, and the other integrated ESP descriptors with molecular surface area $\left(A_{S}\right)$, were firstly constructed. Mechanistic interpretations of the structural descriptors introduced were elucidated in terms of solute-solvent intermolecular interactions. Subsequently, several up-to-date modeling techniques, including support vector machine (SVM), least-squares support vector machine (LSSVM), random forest (RF) and Gaussian process (GP), were utilized to build the nonlinear models. Systematical validations including leave-one-out cross-validation, the validation for test set, as well as a more rigorous Monte Carlo cross-validation were performed to verify the reliability of the constructed models. The predictive performances of the four different nonlinear modeling methods follow the order of LSSVM $\approx \mathrm{GP}>\mathrm{RF}>\mathrm{SVM}$. The pure-ESP-based models are generally inferior to the $A_{S}$-integrated ones. Comparisons with previous results were made.

Keywords: hydrophobic index, electrostatic potential, structural descriptor, QSPR, platinum complex, nonlinear modeling

Abbreviations: ESP, electrostatic potential; GP, Gaussian process; LOO, leave-one-out; LSER, linear solvation energy relationship; LSSVM, least-squares support vector machine; MCCV, Monte Carlo cross-validation; MLR, multiple linear regression; QSPR/QSAR, quantitative structure-property/activity relationship; $\mathrm{R}^{2}$, coefficient of determination; RF, random forest; RMSEE, root mean square error of estimation; RMSCV, root mean square error of cross-validation; RMSEP, root mean square error of prediction; SVM, support vector machine. 


\section{Introduction}

Hydrophobicity, often expressed as the logarithm of the partition coefficient of a compound distributed between immiscible phases of $n$-octanol and water $(\log P)$, is undoubtedly of outstanding importance in the research fields of pharmacological and environmental sciences $[1,2]$. Experimental determination of $\log P$ is an expensive and labor-intensive task, and sometimes, restricted by lack of solutes with high purity. It is therefore of great significance to seek alternative approaches to estimate accurately the $\log P$ values. So far, a host of approaches and related software tools for this purpose have been developed and summarized in several review papers [3-6]. These approaches can be roughly divided into two categories, substructure and whole-molecule approaches. In the whole-molecule approach, the molecule is treated as an entirety. Structural descriptors are calculated firstly, and then, the quantitative relationship between these structural descriptors and $\log P$ is established with different statistical methods.

Physicochemical properties of chemical substances are usually associated with intermolecular non-covalent interactions. It has been proven to be feasible to predict the physicochemical properties with quantitative structure-property relationship (QSPR) models constructed from characteristics of molecular surface, or more exactly, from structural descriptors based on molecular surface [7-10]. Molecular electrostatic potential (ESP) is a quantum-mechanical quantity with rigorous definition [11]. It has received extensive applications due to the capability of characterizing local or site-specific properties of a molecule [12,13]. Moreover, a group of descriptors based on ESPs (mostly on molecular surface) put forward by Politzer and Murray, have been successfully applied in various QSPR studies [14-20].

Following up these previous advances, we introduced the concept of independent surface ESP and developed a series of new statistically-based descriptors [21-26]. It was indicated that these descriptors are fairly effective for correlating and predicting a variety of solution, liquid phase and binding physicochemical properties that depend upon non-covalent interactions [20]. Especially, this set of descriptors can be well used to describe the quantitative structure-hydrophobicity relationship not only for organic compounds with subtle structural difference $[21,22]$, but also for substituent groups $\left(\pi_{\mathrm{X}}\right)$ and even molecular fragments $\left(f_{\text {oct }}\right)[26]$.

As compared to common organic compounds, metal complexes have quite 
different bonding mode and electronic structures. Obviously, it is usually difficult to predict the physicochemical properties of metal complexes from molecular structures due to computational complexity or sometimes lack of relevant parameters. Thus, it would be beneficial to know whether the structure descriptors derived from ESPs on molecular surface, that are often used for common organic compounds, can also be applied to estimate the physicochemical properties of the metal complexes.

Among metal complexes, $\mathrm{Pt}(\mathrm{II})$ complexes are of great importance and continuing interest in chemistry and pharmaceutical fields [27-29]. The discovery of cisplatin, cis- $\left[\mathrm{PtCl}_{2}\left(\mathrm{NH}_{3}\right)_{2}\right]$, represents a milestone in the history of antitumor agents [27]. Pt(IV) complexes, serving as prodrugs, can be reduced to the corresponding $\mathrm{Pt}(\mathrm{II})$ counterparts upon losing the axial ligands in the hypoxic tumor milieu, and as compared to the latter, they show relative inertness and consequent low systemic toxicity outside the cell [30]. Accordingly, their synthesis, physicochemical properties as well as biological behaviors have also aroused wide attention in recent years [31-33].

Platts and coworkers [34] reported the QSPR models based on exposed surface areas of polar and nonpolar atoms to predict the hydrophobicity of platinum complexes. Similar works have since been published in the literature [35-40]. The quality and reliability of early models are generally low since available experimental data is really limited and the sample size used for modeling is too small. Recently, with the accumulation of experimental data, structural diversity of the complexes has increased, and the reliability of the model has been significantly improved. Some statistical models based on atomic additivity (substructure method) have also been developed to directly calculate the $\log P$ of platinum complexes [38].

In this paper, we report new descriptors derived from ESPs on molecular surface, focusing on the quantitative structure-hydrophobicity relationship of $\operatorname{Pt}(\mathrm{IV})$ complexes. It would provide a new approach for predicting the physicochemical properties of metal complexes.

\section{Computational details}

All quantum chemical calculations were performed with the Gaussian 09 software package [41]. Firstly, the initial geometry of each Pt(IV) complex was optimized with the hybrid functional B3LYP method using mixed basis set (SDD effective core potential for Pt and 6-31+G(d,p) for other atoms). In previous comparative tests for Pt 
complexes, this level of theory was proven to reproduce well the molecular structures and NMR spectra [42]. Based on the optimized geometries, electronic densities and ESPs were calculated with grid method. The grid control option was set to "cube = 100 ", and therefore, about $100^{3}$ values of electronic density and ESP were computed for each molecule. Subsequently, the points on molecular surface (the outer isodensity envelope of $\rho(\mathrm{r})=0.001$ a.u.) as well as their ESP values were extracted. Then, a total of 33 descriptors derived from these ESPs, were calculated by using an in-house program. Some of these structural descriptors, e.g. spatial and surface extrema of the ESPs, average positive or negative ESPs, $\sigma_{\text {tot }}^{2}$ and $v$ (vide infra), were suggested by Politzer et al. [19,20], and most were developed or modified in our group [21-26].

Correlations of the descriptors with the hydrophobicity index were established with multiple linear regression (MLR) analysis. Several up-to-date modeling techniques including support vector machine (SVM) [43], least-squares support vector machine (LSSVM) [44], random forest (RF) [45] and Gaussian process (GP) [46] were also adopted with expect to yield better predictive models.

The stability and predictive power of these models were verified by leave-one-out (LOO) and rigorous Monte Carlo cross-validation (MCCV) [47]. In MCCV, the whole data set was split randomly into a training set and a test set in 3:1 ratio and an external $R^{2}\left(R_{\text {ext }}^{2}\right)$ was used as the evaluation criterion. It was calculated from the following formula [48].

$$
R_{\text {ext }}^{2}=1-\frac{\sum_{i=1}^{n_{\text {test }}}\left(y_{i}^{\text {expl }}-y_{i}^{\text {pred }}\right)^{2}}{\sum_{i=1}^{n_{\text {test }}}\left(y_{i}^{\text {expl }}-\bar{y}_{t r}\right)^{2}}
$$

where $\bar{y}_{t r}$ is the averaged value of the response variables for the training set, $y_{i}^{\text {expl }}$ and $y_{i}^{\text {pred }}$ are experimental and predicted values of the test set, respectively. Each cross-validation calculation yielded a $R_{\text {ext }}^{2}$ value, and the process was repeated $2^{16}=65536$ times. From these results the cumulative distribution function of $R_{\text {ext }}^{2}$ is estimated by:

$$
P_{\text {cum }}\left(R_{\text {ext }}^{2}<x\right)=\int_{-\infty}^{x} p\left(R_{\text {ext }}^{2}\right) d x
$$

where $p\left(R_{\text {ext }}^{2}\right)$ is the probability density of $R_{\text {ext }}^{2}$. The median $R_{\text {ext }}^{2}$ corresponds to an $x$ value of $P_{\text {cum }}=0.5$, which represents the demarcation dividing the whole sampled $R_{\text {ext }}^{2}$ equally. The integral $R_{\text {ext }}^{2}$ is defined by the following formula.

$$
\text { integral } R_{\text {ext }}^{2}=\int_{0}^{1}\left[1-P_{\text {cum }}\left(R_{\text {ext }}^{2}<x\right)\right] d x
$$


It describes the distribution of the entire $R_{\text {ext }}^{2}$ probability density, and its value lies between 0 and 1 . The peak $R_{\text {ext }}^{2}$ is the peak position of $R_{\text {ext }}^{2}$ probability density and indicates the most probable location of sampled $R_{\text {ext }}^{2}$. The peak, median and integral $R_{\text {ext }}^{2}$ values were served as the measures of model quality.

\section{Results and Discussion}

\subsection{The QSPR models for $\log k_{0}^{\prime}$}

The data set was taken from previous publication [36]. The hydrophobic indexes expressed as $\log k_{0}^{\prime}$ ( $k_{0}^{\prime}$ is the HPLC capacity factor extrapolated to $100 \%$ water) for $53 \mathrm{Pt}(\mathrm{IV})$ complexes are collected in Table 1. The original data set was first split into a training set and test set in the ratio of $3: 1$. The 13 complexes in the test set were randomly selected as those numbered as $4 \mathrm{n}$ and marked with asterisks in Table 1 .

By using stepwise linear regression and selecting pure ESP-based structural descriptors as independent variables, a four-parameter QSPR model (Eq. (4)) was firstly established for the training set as follow:

$$
\begin{gathered}
\log k_{0}^{\prime}=0.0695 * N_{s, \text { ind }}^{+}-0.0393 * 2 V_{s, \text { ind }}^{+}-18.9985 * \overline{V_{s, \text { ind }}^{0,+}}-14.9856 * v_{\text {ind }}+3.0721 \\
N=40, R^{2}=0.87, R M S E E=0.69, R_{C V}^{2}=0.81, R M S C V=0.82, R_{\text {Pred }}^{2}=0.77, R M S E P=0.83
\end{gathered}
$$

where and throughout this paper, $N$ is the number of data points submitted for regression; $R^{2}$ and $R M S E E$ are fitting coefficient of determination and root mean square error of estimation; $R_{C V}^{2}$ and $R M S C V$ are LOO cross-validation coefficient and root mean square error of LOO cross-validation; $R_{\text {Pred }}^{2}$ and $R M S E P$ are predictive coefficient of determination and root mean square error of prediction.

Considering the fact that the hydrophobicity of a compound is generally associated with molecular size, we also incorporated molecular volume and molecular surface area $\left(A_{S}\right)$ in the MLR analysis and obtained a similar four-parameter model (Eq. (5)).

$$
\begin{gathered}
\log k_{0}^{\prime}=0.0227 * A_{s}-9.6066 * v-20.5437 * \overline{V_{s, \text { ind }}^{0,+}}-0.0653 * N_{s, \text { ind }}^{-}+2.7300 \\
N=40, R^{2}=0.89, R M S E E=0.64, R_{C V}^{2}=0.85, R M S C V=0.73, R_{\text {Pred }}^{2}=0.87, R M S E P=0.63
\end{gathered}
$$

It can be seen that, as compared to Eq. 4, Eq. 5 shows larger $R^{2}, R_{C V}^{2}$ and $R_{\text {Pred }}^{2}$ values, and smaller RMSEE, RMSCV and RMSEP values, which means that the 
$A s$-integrated QSPR model has better fitting and predictive power. Nevertheless, the difference in statistical quality between the two models is not quite large, and both would be taken into account in subsequent discussion. Using Eqs. 4 and 5, we predicted the hydrophobicity for all complexes. The results are tabulated in Table S1 as supporting information. The plots of predicted versus experimental $\log k_{0}^{\prime}$ values for both the training set and the test set shows good fitting (Fig. 1).

As more than one variable are introduced in the models, it is necessary to examine the stability of the regression equations. Upon investigating the collinearity of variables in Eqs. 4 and 5, we obtained the variance inflation factor (VIF) for each descriptor (Table S2). According to statistics principle [49], a value of 1.0 is indicative of no correlation, while a value less than 10.0 is statistically acceptable. It is shown that all of the VIF values are less than 2.0, indicating that the stability of the QSPR models constructed are highly satisfactory.

\subsection{Mechanistic interpretation of the descriptors involved}

$A_{S}$ reflects the size of a molecule and has been demonstrated to be an important descriptor in determining partition coefficients of organic compounds. It is presented in Eq. 5 and positively correlated with $\log k_{0}^{\prime}$, which indicates that the $\operatorname{Pt}(\mathrm{IV})$ complex with larger size is more liable to distribute into nonpolar phase. According to the concept of linear solvation energy relationship (LSER) [50], $A_{S}$ (or molecular volume) can be viewed as a cavity term, which is a measure of the energy needed to overcome the cohesive forces in order to form a cavity for the solute, and the larger molecules would tend to be excluded from the more polar solvent water.

All other structural descriptors included in Eqs. 4 and 5 are derived statistically from the ESPs on molecular surface. Five of them are associated with the independent ESPs, and among which $\overline{V_{s, \text { ind }}^{0,+}}$ appeared for the first time in our QSPR/QSAR studies. The so-called independent ESPs refer to the statistically calculated ESPs of those points on molecular surface with pairwise distance of above $0.21 \mathrm{~nm}$. The cutoff value $0.21 \mathrm{~nm}$ is the arithmetic mean value between the van der Waals radius of a water molecule $(0.14 \mathrm{~nm})$ and the diameter of the water molecule $(0.28 \mathrm{~nm})$ [21].

$\Sigma V_{s, \text { ind }}^{+}$is the sum of the independent positive ESPs. The summation starts from the most positive ESP on molecular surface $\left(V_{s, \max }\right)$, and the corresponding position of $V_{s, \max }$ is viewed as the first independent point. Then the next $V_{s, \max }$ is considered, and 
it is added in the summation only if its distance from the former independent point is larger than $0.21 \mathrm{~nm}$. This operation is repeated until all of the independent points with positive ESPs are included. This descriptor also appeared in previous QSPR modeling for $\log P$ of halogenated methylphenyl ethers [51]. As $2 V_{s, \text { ind }}^{+}$reflects nonspecific intermolecular interactions, it is presented in Eq. 4 and negatively correlated with $\log k_{0}^{\prime}$, indicating that the Pt(IV) complexes with larger positive ESPs tend to interact with water and show lower lipophilicity.

$N_{S, \text { ind }}^{+}$is the number of independent points of positive ESPs on molecular surface. It is the first variable introduced in the model (Eq. 4) upon stepwise regression analysis and can explain about $75 \%$ of the variance of experimental $\log k_{0}^{\prime}$ value. As compared to $2 V_{s, \text { ind }}^{+}, N_{s, \text { ind }}^{+}$represents opposite contribution to the lipophilicity, implying that the complexes distributing with more small positive surface ESPs would be favorable for partition into organic phase (vide infra).

$N_{s, \text { ind }}^{-}$is the number of independent negative ESPs on molecular surface counting from the most negative ESPs. This term contributes negatively to the lipophilicity, which means that the Pt(IV) complex with more negative ESP region also tends to partition into water phase. This makes sense since water is a typical amphiphilic polar molecule (both a good electron donor and a good electron acceptor), and the existence of a large ESP region in the compound, whether positive or negative, is in favor of its interacting with water molecule.

The hydrophobicity and hydrophilicity of a molecule is closely related to the uniformity of ESP distribution on molecular surface [16,18,52]. v, defined as Eq. 6, is a descriptors reflecting uniformity of distribution of $\operatorname{ESPs}\left(\bar{V}_{s}, \overline{V_{s}^{-}}\right.$and $\overline{V_{S}^{+}}$are the average values of surface ESPs, positive and negative surface ESPs, respectively). $v$ is an indicator of the degree of balance between the positive and negative surface potentials, and it reaches a maximum of 0.25 when $\sigma_{+}^{2}=\sigma_{-}^{2} \cdot \sigma_{\text {tot }}^{2}$ is generally viewed as a measure of electrostatic interaction tendency. Compared to $\Pi$, another similar descriptor, it emphasizes the contribution of the extremum and is more sensitive to the variation of the surface ESPs [19,20]. In fact, $\Pi$ and $\sigma_{\text {tot }}^{2}$ have been frequently introduced in previous QSPR models [16,26]. In this work, $v$ and $v_{\text {ind }}$ (balance parameter for the independent ESPs) are found to be statistically significant and give negative contribution to $\log k_{0}^{\prime}$, manifesting that the distribution uniformity of ESPs play important role in the hydrophobicity of $\mathrm{Pt}(\mathrm{IV})$ complex. The $\mathrm{Pt}(\mathrm{IV})$ 
complex with more balanced positive and negative surface ESPs distribution are favorable to enhance the lipophilicity.

$$
\begin{aligned}
& v=\frac{\sigma_{+}^{2} \cdot \sigma_{-}^{2}}{\left(\sigma_{\text {tot }}^{2}\right)^{2}} \\
& \sigma_{\text {tot }}^{2}=\sigma_{+}^{2}+\sigma_{-}^{2}=\frac{1}{m} \sum_{i=1}^{m}\left|V^{+}\left(r_{i}\right)-\overline{V_{s}^{+}}\right|^{2}+\frac{1}{n} \sum_{i=1}^{n}\left|V^{-}\left(r_{i}\right)-\overline{V_{s}^{-}}\right|^{2}
\end{aligned}
$$

As mentioned above, the presence of large positive or negative ESPs on the molecular surface is in favor of interacting with water molecule, and therefore detrimental for the lipophilicity. On the contrary, the contour surface of a typical hydrophobic molecule or fragment (e.g. alkyl group) is usually distributed with small and uniform positive ESPs [16,18,52]. With this in mind, we constructed a group of new descriptors based on statistical calculations starting from the surface ESPs closest to zero, and one of them, $\Sigma V_{s, i n d}^{0,+}$, has been utilized to predict the complexation of structurally diverse compounds with $\beta$-cyclodextrin [23]. In the present work, another descriptor of this type, $\overline{V_{s, i n d}^{0,+}}$, has been found to be statistically significant and was introduced in both models. $\overline{V_{s, i n d}^{0,+}}$ is the average of independent positive ESPs on molecular surface ranging from 0 to 0.01 a.u.. It makes a negative contribution to $\log k_{0}^{\prime}$, meaning that the smaller the absolute value of these tiny positive ESPs, the more favorable it is for lipophilicity. This is consistent with aforementioned analysis.

\subsection{Nonlinear models}

As shown above, the linear models provide satisfactory predictive power and good interpretability. Nevertheless, non-linear models usually give better results. Accordingly, we use several up-to-date non-linear statistical methods, including SVM, LSSVM, RF and GP to deal with the present data set. The input parameters are the structure descriptors introduced in Eqs. 4 and 5. The statistic results of the nonlinear models for both the training set and the test set are displayed in Table 2. For the purpose of comparison, the corresponding values of linear models are also listed. The parameters optimized during the course of nonlinear modeling are summarized in Table S3.

SVM is a machine learning algorithm developed by Vapnik et al. in the framework of the statistical learning theory [43]. It is especially suitable for dealing with 
small-sample, high-dimensional and strong collinear problems due to adopting structural risk minimization (SRM) instead of empirical risk minimization (ERM). LSSVM is developed on the basis of traditional SVM. It introduces a least squares linear system into support vectors, transforms inequality constraints into equality constraints, and converts solving quadratic programming problems into solving linear equations. As a result, the insensitive loss function is avoided, and the computational efficiency is greatly improved [44].

It can be seen from the statistical results given in Table 2, for the training set, the fitting ability and predictive power of SVM and LSSVM have been improved as compared with the linear MLR models (larger $R^{2}$ and $R_{C V}^{2}$, and smaller RMSEE and RMSCV values), whether the pure ESP descriptor set or the $A_{S}$-integrated one was adopted. For the test set, however, the performances of SVM are unusually poor, the $R_{\text {Pred }}^{2}$ values are not larger than 0.70, and the RMSEP values exceed 0.90. Relatively, LSSVM yields significantly better predictive performance than the traditional SVM as well as MLR, as reflected by the statistical results in Table 2 (all of the coefficients of determination, $R^{2}, R_{C V}^{2}$ and $R_{\text {Pred }}^{2}$, are larger than 0.85, and the RMSEP values drop to ca. 0.6 , regardless of the descriptor set used).

Random forest is a flexible, easy to use machine learning algorithm [45]. This type of algorithm helps to enhance the ways that technologies analyze complex data. It is capable of performing both regression and classification tasks with the use of multiple decision trees and a bagging technique. It is necessary to adjust the parameters in the construction of the decision tree to get the final model with the best parameters. In the present work, two adjustable parameters, number of trees $\left(n_{\text {tree }}\right)$ and size of descriptor subset ( $\left.m_{\text {tree }}\right)$, were optimized using grid-searching method. The optimum $n_{\text {tree }}$ and $m_{\text {tree }}$ (see Table S3) were used to construct the final RF model.

As can be seen from the data in Table 2, the $R^{2}$ values of RF models based on the two different descriptor sets are 0.91 and 0.89 , respectively, and the RMSEE values are 0.58 and 0.64 , respectively, which means that the RF models have relatively good fitting ability. However, from the information reflected by other four statistical quantities, $R_{C V}^{2}, R M S C V, R_{P r e d}^{2}$, and $R M S E P$, the predictive performance of the RF models are relatively poor. 
Gaussian process (GP) is a new type of machine learning algorithm developed on the basis of Bayesian framework and has attracted wide interest of researchers in related fields in recent years [53,54]. It has several advantages over the other nonlinear modeling methods, such as no function constraints, being capable of dealing with linear/nonlinear hybrid problems, automatic determination of the model parameters, and probabilistic significance of the output results. Moreover, the GP method can evaluate the validity and confidence of the prediction results [46].

Recently, we applied this method to construct successfully predictive models of the complexation of structurally diverse compounds with $\beta$-cyclodextrin [23], the bioconcentration factor of nonionic compounds [24], and the minimum alveolar concentration of anesthetic agents [25]. In the current study, we use the general covariance function as the kernel function, which consists of a constant term, a linear term, a square exponential term, and a noise term. The corresponding hyperparameters $\theta_{0}$ (constant term), $\theta_{1}$ (linear term), $\theta_{2}$ (square exponential term), and $\sigma_{v}^{2}$ (noise term) are optimized by conjugate gradient method and displayed in Table S3.

For the training set, the $R^{2}$ values given by GP modeling are 0.94 (Pure ESP-based) and 0.92 ( $A_{S}$-integrated), and the RMSEE values are 0.46 and 0.53 , respectively. The former yields the best fitting ability among all of the models. The performances of GP models, however, are not as excellent as one might expected, from the statistical results of LOO-CV as well as those for the test set. The $R_{C V}^{2}$, $R M S C V, R_{P r e d}^{2}$ and RMSEP values of the As-integrated GP models are almost the same as those of the linear model. This means that the linear components are predominant in the GP modeling, which is supported by the optimized hyperparameters $\theta_{0}, \theta_{1}$ and $\theta_{2}\left(\theta_{0}, \theta_{1}>\theta_{2}\right)$.

Additionally, one of the advantages of the GP method over the other nonlinear modeling techniques lies in that the importance of different descriptors can be measured by the length scales $r_{i}$. Each $r_{i}$ is associated with an input and characterizes the distance in the $i$ th direction over which output is expected to vary significantly. A small $r_{i}$ value corresponds to a relatively important descriptor, whereas a large $r_{i}$ value means that the variation of the corresponding descriptor does not influence the 
property very much. It has been shown that all of the $r_{i}$ values (see Table S4) are less than 3, which means that all the descriptors in Eqs. 4 and 5 are significant for the hydrophobicity of $\mathrm{Pt}(\mathrm{IV})$ complexes. Relatively, $2 V_{s, \text { ind }}^{+}$and the balance parameter $v$ give more important contributions.

Comparing the data listed in Table 2, it is not difficult to infer that the predictive performances of the four different nonlinear modeling methods follow the order of $\mathrm{LSSVM} \approx \mathrm{GP}>\mathrm{RF}>\mathrm{SVM}$. As for comparison between the pure-ESP-based models and the $A_{S}$-integrated ones, the former is in general inferior to the latter. The predicted $\log k_{0}^{\prime}$ values by the LSSVM and GP models are displayed in Table S2. The plots of predicted versus experimental results are illustrated in Fig. 1, from which the fitting and predictive power of these models can be visually compared.

\subsection{Monte Carlo cross-validation tests}

As stated above, the samples in the test set (13 complexes) are randomly selected. Nevertheless, such selection is featured of inherent arbitrariness, and the validation using one single test set is undoubtedly deficient from the point of statistics. In order to systemically test the predictive power of the QSPR models, we used MCCV method with up to $2^{16}=65536$ samplings to perform rigorous validations. Table 2 lists the peak, median and integral $R_{\text {ext }}^{2}$ values. For the pure-ESP-based linear model, they are $0.88,0.82$ and 0.79 , respectively, while for the $A s$-integrated linear model, these three values are $0.90,0.86$ and 0.83 , respectively. Except the integral $R_{\text {ext }}^{2}$ values of the former, they are all larger than 0.80, demonstrating that both linear models have considerably good stability and predictive power. As for the four nonlinear modeling methods, the $\mathrm{MCCV}$ results reveal that their predictive performances follow the same order as the results of the single test set. The LSSVM and GP models are slightly better than the corresponding linear model, and the SVM and RF models are significantly worse.

\subsection{Comparison with previous results}

There have been several reports in the literature about the prediction of the lipophilicity of platinum complexes. However, due to the difference in complex sets adopted, and in some cases, $\mathrm{Pt}(\mathrm{IV})$ complexes have been mixed with $\mathrm{Pt}(\mathrm{II})$ complexes 
together for modeling, direct comparison is often difficult.

Ermondi et al. [36] performed a modeling study with the molecular-interactionfields (MIF) based method for the same data set. They used four types of probes and a total of 92 Volsurf descriptors, and obtained the statistical results as follows: $R^{2}(\mathrm{LOO})=0.87, R^{2}(3$ - and 4 -fold $)=0.85$. For comparison, we have done a similar calculation with partial least squares (PLS) method using all 33 ESP-based descriptors plus $A s$, resulting in $R^{2}(\mathrm{LOO})=0.85, R^{2}(3$-fold $)=0.83$ and $R^{2}$ (4-fold $)=0.82$. The statistical quality of our model is roughly equivalent to that of MIF-based one.

Tetko et al. [38] used fragment-based and whole-molecule methods to develop several models for predicting the lipophilicity of platinum complexes. Particularly, they provided a website for the public to predict the $\log P$ of new Pt complexes. In that work, some models only for the Pt(IV) complexes were reported. In order to make a proper comparison, and meanwhile, to test further the applicability of the ESP-derived descriptors, we performed a QSPR treatment, following the same workflow, for all $122 \mathrm{Pt}(\mathrm{IV})$ complexes reported by Tetko et al. (51 of them are duplicates of the complexes considered in this work, see supporting information). Using the same training set of 87 complexes as Tetko et al. adopted, we obtained a four-parameter model similar to Eq. 5 as follows:

$\log P=0.0139 * A_{s}+0.0673 * V_{s, \max }-0.0158 * N_{s, \text { ind }}^{-}-0.0109 * D_{s, \text { extrm }}-3.6208$

$N=87, R^{2}=0.74, R M S E E=0.73, R_{C V}^{2}(5$-fold $)=0.71, \operatorname{RMSCV}(5$-fold $)=0.75$

Eq. 7 is evidently inferior to Eq. 5, and there is a certain gap between the results and what we expected. Furthermore, two nonlinear modeling methods that performed well in prior work, LSSVM and GP, were used to deal with the data set, but no significantly improvement was found. For the test set consisting of the remaining 35 complexes, this linear model gives $R_{\text {pred }}^{2}=0.59$ and $R M S E P=0.84$.

This result certainly cannot be compared with the best result of Tetko et al. (the cross-validated RMSE values of the associative neural network modeling were 0.36 and 0.66 respectively for the training set and the test set). Nevertheless, it is still acceptable when compared with their MLR results $\left(R_{C V}^{2}(5\right.$-fold $)=0.3-0.78$ and $\operatorname{RMSCV}(5$-fold $)=0.72-1.28$ for the combined set $\mathrm{Pt}(\mathrm{II})$ and $\mathrm{Pt}(\mathrm{IV})$, no results found for 
Pt(IV) alone), especially considering the good interpretability of the descriptors.

One of main reasons for the unsuccess of the models established for the $53 \mathrm{Pt}(\mathrm{IV})$ complexes to extend to a larger data set is that the 33 descriptors derived from ESPs on molecular surface provide relatively limited information. At present, there are still some deficiencies in QSPR modeling of complex compounds and in QSAR modeling. New descriptors of this type have been developing in our laboratory to extend their applicability.

\section{Summary and Conclusions}

Metal complexes exhibit quite different bonding mode and electronic structure from common organic compounds. It is usually difficult to predict the physicochemical properties of metal complexes from molecular structures due to computational complexity or the lack of relevant parameters. The present paper was aimed at answering the question whether the physicochemical properties of the metal complexes can be predicted regardless of their internal bonding mode and base on molecular surface properties that are often used for common organic compounds. For this purpose, quantitative structure-hydrophobicity relationship for a group of $\operatorname{Pt}(\mathrm{IV})$ complexes was investigated by using the structure descriptors derived from electrostatic potentials (ESPs) on molecular surface.

A four-parameter equation with pure-ESP based descriptors was firstly constructed for the training set consists of $40 \mathrm{Pt}(\mathrm{IV})$ complexes. Incorporation of an additional descriptor reflecting molecular size $\left(A_{S}\right)$ in the modeling resulted in a similar four-parameter equation. A collinearity diagnosis of variables revealed that the VIF values of all descriptors are less than 2.0, demonstrating the robustness of the models. Both models were further validated by rigorous MCCV calculations and showed good stability and predictive power.

Mechanistic interpretations of the structural descriptors introduced were elucidated from the point of view of solute-solvent intermolecular interactions. Especially, $\overline{V_{s, i n d}^{0,+}}$ derived from statistical calculations of the independent surface ESPs ranging from 0 to 0.01 a.u., appeared for the first time in our QSPR/QSAR studies.

Four up-to-date modeling techniques, including SVM, LSSVM, RF and GP, were utilized to build the nonlinear models. The predictive performances of GP and 
LSSVM modeling are satisfactory, as reflected by the statistical results in Table 2. The SVM and RF methods represent poor performance, even worse than the MLR method.

Finally, comparisons with previous predictive models in the literature were made. The results show that the statistical quality of our model constructed with only a few structural descriptors in relation to molecular surface properties is roughly comparable to that of the MIF-based model for the same data set.

\section{Acknowledgements}

The authors are grateful to the Natural Science Foundation of China (Project No. 21272211) and the Program of Science and Technology of Ningbo, China (2019C10083) for financial support.

\section{Declaration of competing interest}

The authors have no conflicts of interest.

\section{Appendix A. Supplementary data}

Supplementary data associated with this article can be found online at doi: https://doi.org/10.1016/j.jinorgbio.****.

\section{References}

[1] A. Sarkar, G.E. Kellogg, Curr. Top. Med. Chem. 10 (2010) 67-83.

[2] A.J. Leo, C. Hansch, Perspect. Drug Discov. Design 17 (1999) 1-25.

[3] A.J. Leo, Chem. Rev. 93 (1993) 1281-1306.

[4] R. Mannhold, G.I. Poda, C. Ostermann, I.V. Tetko, J. Pharm. Sci. 98 (2009) 861-893.

[5] D.E. Smith, A.D.J. Haymet, Rev. Comput. Chem. 19 (2003) 43-77.

[6] R. Mannhold, H. van de Waterbeemd, J. Comput.-Aid. Mol. Design 15 (2001) 337-354.

[7] T. Clark, J. Mol. Graph. Model. 22 (2004) 519-525.

[8] J. Polanski, B. Walczak, Comput. Chem. 24 (2000) 615-625.

[9] L. Michielan, M. Bacilieri, C. Kaseda, S. Moro, Biorg. Med. Chem. 16 (2008) 5733-5742.

[10] J. Kelder, P.D.J. Grootenhuis, D.M. Bayada, L.P.C. Delbressine, J.P. Ploemen, Pharm. Res. 16 (1999) 1514-1519.

[11] J.S. Murray, P. Politzer, Wiley Interdisc. Rev. Comput. Mol. Sci. 1 (2011) 153-163.

[12] C.H. Suresh, S.R. Gadre, J. Phys. Chem. A 111 (2007) 710-714.

[13] J.W. Zou, Y.J. Jiang, M. Guo, G.X. Hu, B. Zhang, H.C. Liu, Q.S. Yu, Chem. Eur. J. 11 (2005) 
740-751.

[14] O. Lamarche, J.A. Platts, A. Hersey, J. Chem. Inf. Comput. Sci. 44 (2004) 848-855.

[15] J.S. Murray, F. Abu-Awwad, P. Politzer, J. Phys. Chem. A 103 (1999) 1853-1856.

[16] M. Haeberlein, T. Brinck, J. Chem. Soc. Perkin Trans. 2 (1997) 289-294.

[17] J.S. Murray, P.G. Seybold, R. Battino, P. Politzer, J. Mol. Model. 26 (2020) 244.

[18] Q.S. Du, G.A. Arteca, J. Comput.-Aid. Mol. Design 10 (1996) 133-144.

[19] F.A. Bulat, A. Toro-Labbe, T. Brinck, J.S. Murray, P. Politzer, J. Mol. Model. 16 (2010) 1679-1691.

[20] J.S. Murray, P. Politzer, Wiley Interdisc. Rev. Comput. Mol. Sci. 7 (2017) e13260.

[21] J.W. Zou, W.N. Zhao, Z.C. Shang, M.L. Huang, M. Guo, Q.S. Yu, J. Phys. Chem. A 106 (2002) $11550-11557$.

[22] H.-Y. Xu, J.-W. Zou, G.-X. Hu, W. Wang, Chemosphere 80 (2010) 665-670.

[23] P. Sang, J.-W. Zou, D.-M. Dai, G.-X. Hu, Y.-J. Jiang, Chemo. Intel. Lab. Syst. 127 (2013) 166-176.

[24] P. Sang, J.-W. Zou, P. Zhou, L. Xu, Chemosphere 83 (2011) 1045-1052.

[25] P. Sang, J.-W. Zou, Y.-L. Yu, M.-L. Huang, Chemo. Intel. Lab. Syst. 112 (2012) 8-16.

[26] J.-W. Zou, M. Huang, J.-X. Huang, G.-X. Hu, Y.-J. Jiang, J. Mol. Graph. Model. 64 (2016) $110-120$

[27] F. Trudu, F. Amato, P. Vanhara, T. Pivetta, E.M. Pena-Mendez, J. Havel, J. Appl. Biomed. 13 (2015) 79-103.

[28] S. Dasari, P.B. Tchounwou, Eur. J. Pharmacol. 740 (2014) 364-378.

[29] T. Boulikas, M. Vougiouka, Oncol. Rep. 10 (2003) 1663-1682.

[30] Y. Shi, S.-A. Liu, D.J. Kerwood, J. Goodisman, J.C. Dabrowiak, J. Inorg. Biochem. 107 (2012) 6-14.

[31] M.D. Hall, T.W. Hambley, Coord. Chem. Rev. 232 (2002) 49-67.

[32] A.S. Kritchenkov, Y.M. Stanishevskii, Y.A. Skorik, Pharm. Chem. J. 53 (2019) 6-14.

[33] Z. Deng, N. Wang, Y. Liu, Z. Xu, Z. Wang, T.-C. Lau, G. Zhu, J. Am. Chem. Soc. 142 (2020) 7803-7812.

[34] J.A. Platts, D.E. Hibbs, T.W. Hambley, M.D. Hall, J. Med. Chem. 44 (2001) 472-474.

[35] A.A. Toropov, A.P. Toropova, Chem. Phys. Lett. 701 (2018) 137-146.

[36] G. Ermondi, G. Caron, M. Ravera, E. Gabano, S. Bianco, J.A. Platts, D. Osella, Dalton Trans. 42 (2013) 3482-3489.

[37] S.P. Oldfield, M.D. Hall, J.A. Platts, J. Med. Chem. 50 (2007) 5227-5237.

[38] I.V. Tetko, H.P. Varbanov, M. Galanski, M. Talmaciu, J.A. Platts, M. Ravera, E. Gabano, J. Inorg. Biochem. 156 (2016) 1-13.

[39] G. Caron, M. Ravera, G. Ermondi, Pharm. Res. 28 (2011) 640-646.

[40] J.A. Platts, G. Ermondi, G. Caron, M. Ravera, E. Gabano, L. Gaviglio, G. Pelosi, D. Osella, J. Biol. Inorg. Chem. 16 (2011) 361-372.

[41] M.J. Frisch et al., Gaussian 09, Revision A.1, Gaussian Inc., Wallingford, CT, 2009.

[42] H.W. Gao, X.J. Wei, X.T. Liu, T.X. Yan, J. Phys. Chem. B 114 (2010) 4056-4062. 
[43] R.G. Brereton, G.R. Lloyd, Analyst 135 (2010) 230-267.

[44] R.P. Cogdill, P. Dardenne, J. Near Infrared Spectrosc. 12 (2004) 93-100.

[45] L. Breiman, Machine Learning 45 (2001) 5-32.

[46] M. Seeger, Int. J. Neural Syst. 14 (2004) 69-106.

[47] Q.S. Xu, Y.Z. Liang, Chemo. Intel. Lab. Syst. 56 (2001) 1-11.

[48] V. Consonni, D. Ballabio, R. Todeschini, J. Chem. Inf. Model. 49 (2009) 1669-1678.

[49] D.A. Belesley, E. Kuh, R.E. Welsh, Regression Diagnostics, Wiley, New York, United States, 1990.

[50] M.J. Kamlet, R.M. Doherty, M.H. Abraham, Y. Marcus, R.W. Taft, J. Phys. Chem. 92 (1988) 5244-5255.

[51] H.-Y. Xu, J.-Y. Zhang, J.-W. Zou, X.-S. Chen, J. Mol. Graph. Model. 26 (2008) 1076-1081.

[52] Q.S. Du, G.A. Arteca, P.G. Mezey, J. Comput.-Aid. Mol. Design 11 (1997) 503-515.

[53] O. Obrezanova, G. Csanyi, J.M.R. Gola, M.D. Segall, J. Chem. Inf. Model. 47 (2007) 1847-1857.

[54] P. Zhou, X. Chen, Y. Wu, Z. Shang, Amino Acids 38 (2010) 199-212. 


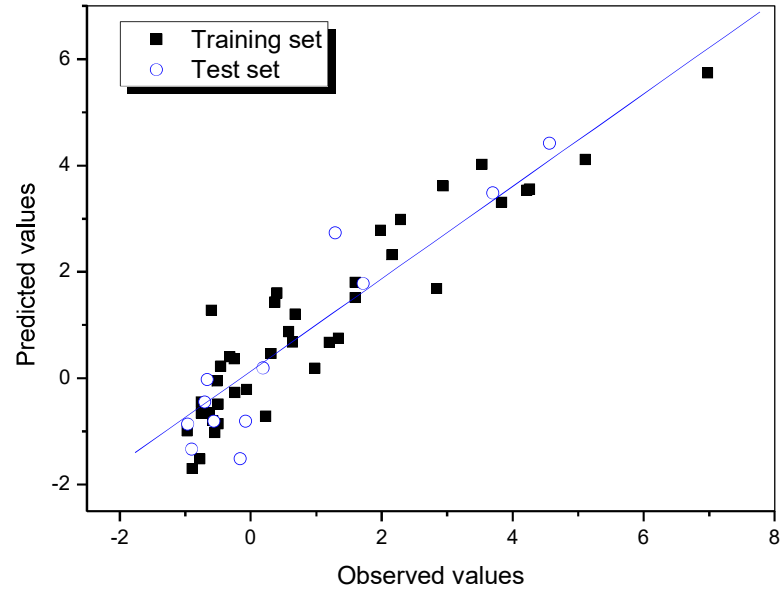

(a) Pure-ESP based MLR model

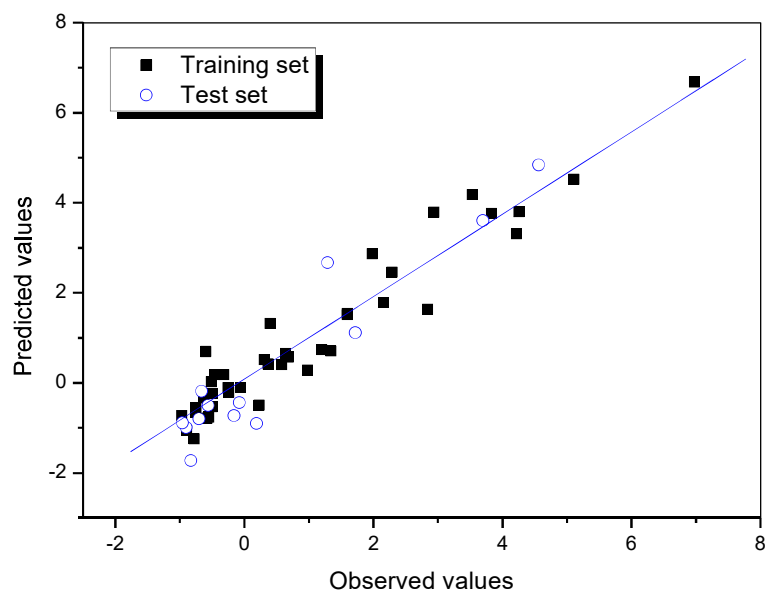

(c) Pure-ESP based LSSVM model

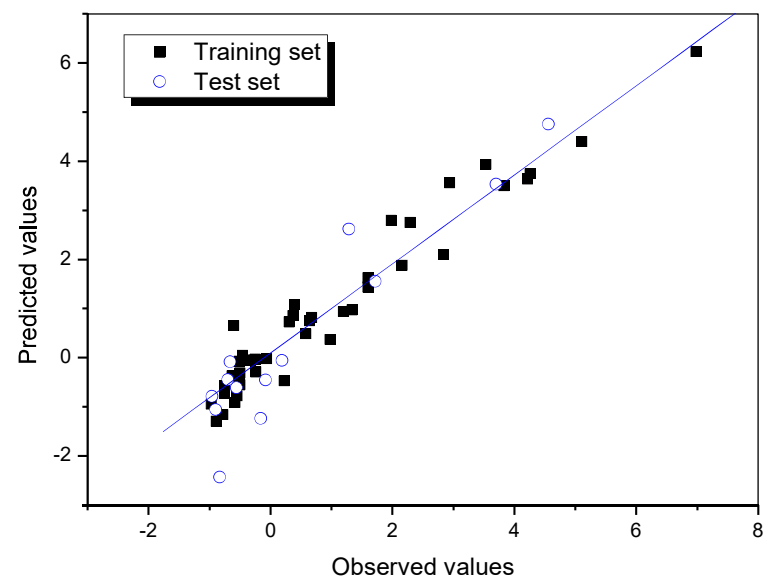

(e) Pure-ESP based GP model

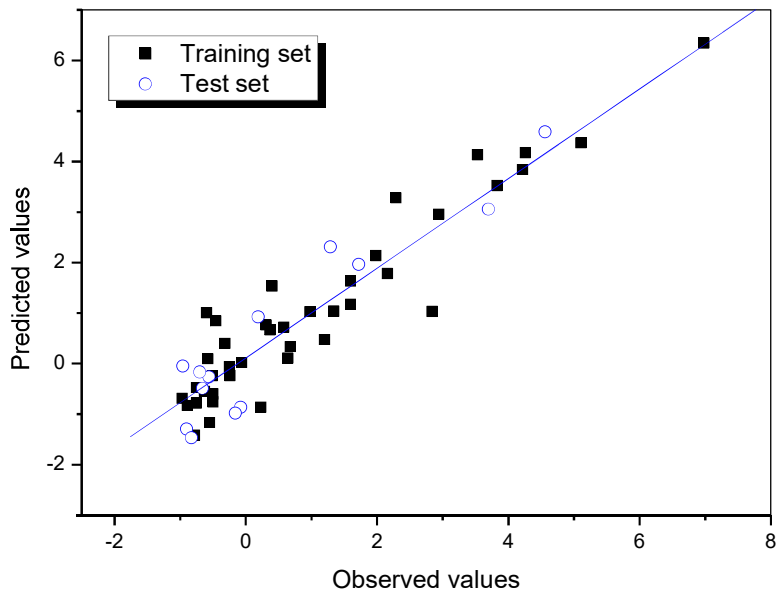

(b) $A s$-integrated MLR model

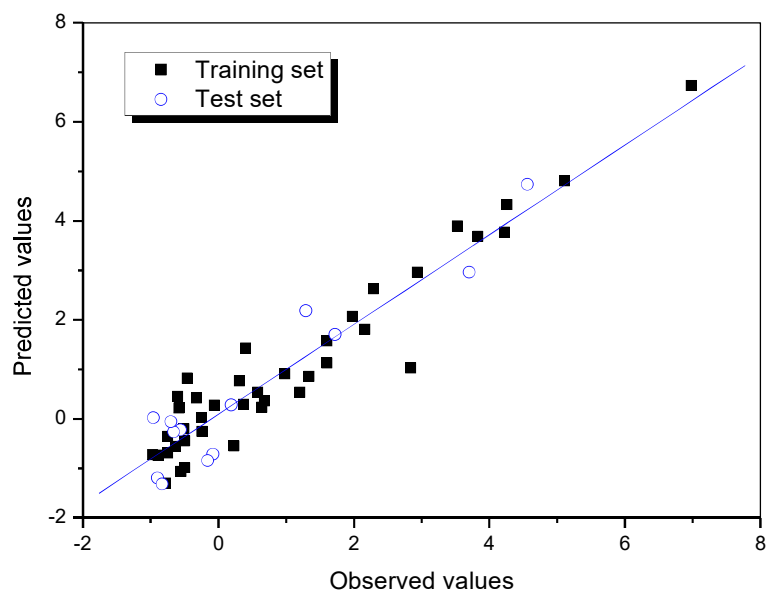

(d) $A_{S}$-integrated LSSVM model

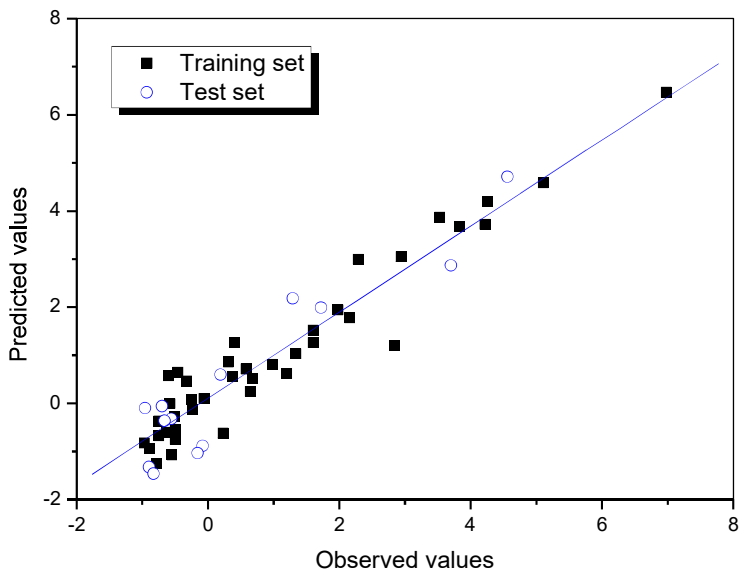

(f) $A_{s}$-integrated GP model

Fig. 1 Plots of predicted versus experimental $\log k_{0}^{\prime}$ values of Pt(IV) complexes 
Table 1 molecular structures of $53 \mathrm{Pt}(\mathrm{IV})$ complexes and their hydrophobic indexes $\log k_{0}^{\prime}{ }^{\mathrm{a}}$

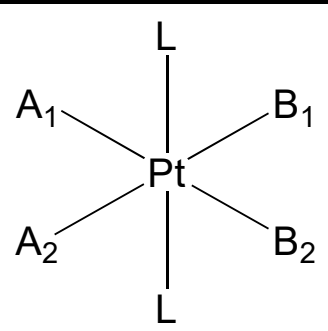

\begin{tabular}{|c|c|c|c|c|c|c|}
\hline No. & $\mathbf{A}_{1}$ & $\mathbf{A}_{2}$ & $\mathbf{B}_{1}$ & $\mathbf{B}_{2}$ & $\mathbf{L}$ & $\log k_{0}^{\prime}$ \\
\hline 1 & $\mathrm{NH}_{3}$ & $\mathrm{NH}_{3}$ & $\mathrm{Cl}$ & $\mathrm{Cl}$ & $\mathrm{OH}$ & -0.97 \\
\hline 2 & $\mathrm{CH}_{3} \mathrm{NH}_{2}$ & $\mathrm{CH}_{3} \mathrm{NH}_{2}$ & $\mathrm{Cl}$ & $\mathrm{Cl}$ & $\mathrm{OH}$ & -0.50 \\
\hline 3 & $\left(\mathrm{CH}_{3}\right)_{2} \mathrm{CHNH}_{2}$ & $\left(\mathrm{CH}_{3}\right)_{2} \mathrm{CHNH}_{2}$ & $\mathrm{Cl}$ & $\mathrm{Cl}$ & $\mathrm{OH}$ & 0.64 \\
\hline $4 *$ & \multicolumn{2}{|c|}{$\mathrm{NH}_{2}\left(\mathrm{CH}_{2}\right)_{2} \mathrm{NH}_{2}$} & $\mathrm{Cl}$ & $\mathrm{Cl}$ & $\mathrm{OH}$ & -0.90 \\
\hline 5 & \multicolumn{2}{|c|}{$\mathrm{CH}_{3} \mathrm{NH}\left(\mathrm{CH}_{2}\right)_{2} \mathrm{NH}_{2}$} & $\mathrm{Cl}$ & $\mathrm{Cl}$ & $\mathrm{OH}$ & -0.75 \\
\hline 6 & \multicolumn{2}{|c|}{$\mathrm{CH}_{3} \mathrm{NH}\left(\mathrm{CH}_{2}\right)_{2} \mathrm{NHCH}_{3}$} & $\mathrm{Cl}$ & $\mathrm{Cl}$ & $\mathrm{OH}$ & -0.55 \\
\hline 7 & \multicolumn{2}{|c|}{$\left(\mathrm{CH}_{3}\right)_{2} \mathrm{~N}\left(\mathrm{CH}_{2}\right)_{2} \mathrm{NHCH}_{3}$} & $\mathrm{Cl}$ & $\mathrm{Cl}$ & $\mathrm{OH}$ & -0.24 \\
\hline $8^{*}$ & \multicolumn{2}{|c|}{$\left(\mathrm{CH}_{3}\right)_{2} \mathrm{~N}\left(\mathrm{CH}_{2}\right)_{2} \mathrm{~N}\left(\mathrm{CH}_{3}\right)_{2}$} & $\mathrm{Cl}$ & $\mathrm{Cl}$ & $\mathrm{OH}$ & -0.08 \\
\hline 9 & $\mathrm{C}_{4} \mathrm{H}_{7} \mathrm{NH}_{2}$ & $\mathrm{C}_{4} \mathrm{H}_{7} \mathrm{NH}_{2}$ & $\mathrm{Cl}$ & $\mathrm{Cl}$ & $\mathrm{OH}$ & 1.20 \\
\hline 10 & $\mathrm{C}_{5} \mathrm{H}_{9} \mathrm{NH}_{2}$ & $\mathrm{C}_{5} \mathrm{H}_{9} \mathrm{NH}_{2}$ & $\mathrm{Cl}$ & $\mathrm{Cl}$ & $\mathrm{OH}$ & 2.16 \\
\hline 11 & $\mathrm{C}_{6} \mathrm{H}_{11} \mathrm{NH}_{2}$ & $\mathrm{C}_{6} \mathrm{H}_{11} \mathrm{NH}_{2}$ & $\mathrm{Cl}$ & $\mathrm{Cl}$ & $\mathrm{OH}$ & 2.84 \\
\hline $12 *$ & $\mathrm{NH}_{3}$ & $\mathrm{NH}_{3}$ & \multicolumn{2}{|c|}{$\square \mathrm{OC}(\mathrm{O}) \mathrm{CH}_{2} \mathrm{C}(\mathrm{O}) \mathrm{O} \square$} & $\mathrm{OH}$ & -0.96 \\
\hline 13 & $\mathrm{CH}_{3} \mathrm{NH}_{2}$ & $\mathrm{CH}_{3} \mathrm{NH}_{2}$ & \multicolumn{2}{|c|}{$\square \mathrm{OC}(\mathrm{O}) \mathrm{CH}_{2} \mathrm{C}(\mathrm{O}) \mathrm{O} \square$} & $\mathrm{OH}$ & -0.75 \\
\hline 14 & \multicolumn{2}{|c|}{$\mathrm{NH}_{2}\left(\mathrm{CH}_{2}\right)_{2} \mathrm{NH}_{2}$} & \multicolumn{2}{|c|}{$\square \mathrm{OC}(\mathrm{O}) \mathrm{CH}_{2} \mathrm{C}(\mathrm{O}) \mathrm{O} \square$} & $\mathrm{OH}$ & -0.89 \\
\hline 15 & $\mathrm{NH}_{3}$ & $\mathrm{NH}_{3}$ & \multicolumn{2}{|c|}{$\mathrm{CBDC}$} & $\mathrm{OH}$ & -0.50 \\
\hline $16^{*}$ & \multicolumn{2}{|c|}{ CHDA } & & & $\mathrm{OH}$ & 0.19 \\
\hline 17 & \multicolumn{2}{|c|}{$\mathrm{CH}_{3} \mathrm{NH}\left(\mathrm{CH}_{2}\right)_{2} \mathrm{NHCH}_{3}$} & \multicolumn{2}{|c|}{$\square \mathrm{OC}(\mathrm{O})-\mathrm{C}(\mathrm{O}) \mathrm{O} \square$} & $\mathrm{OH}$ & -0.58 \\
\hline 18 & $\mathrm{NH}_{3}$ & $\mathrm{NH}_{3}$ & \multicolumn{2}{|c|}{ AAM } & $\mathrm{OH}$ & -0.63 \\
\hline 19 & $\mathrm{NH}_{3}$ & $\mathrm{NH}_{3}$ & \multicolumn{2}{|c|}{ BAM } & $\mathrm{OH}$ & 0.23 \\
\hline $20 *$ & \multicolumn{2}{|c|}{ DAPPA } & $\mathrm{Cl}$ & $\mathrm{Cl}$ & $\mathrm{OH}$ & -0.56 \\
\hline 21 & $\mathrm{CH}_{3} \mathrm{NH}_{2}$ & $\mathrm{CH}_{3} \mathrm{NH}_{2}$ & \multicolumn{2}{|c|}{ BAM } & $\mathrm{OH}$ & 0.98 \\
\hline 22 & $\mathrm{NH}_{3}$ & $\mathrm{NH}_{3}$ & \multicolumn{2}{|c|}{ BAAPM } & $\mathrm{OH}$ & 0.58 \\
\hline 23 & $\mathrm{NH}_{3}$ & $\mathrm{NH}_{3}$ & $\mathrm{Cl}$ & $\mathrm{Cl}$ & $\mathrm{Cl}$ & -0.78 \\
\hline $24 *$ & $\mathrm{NH}_{3}$ & $\mathrm{NH}_{3}$ & $\mathrm{Cl}$ & $\mathrm{Cl}$ & $\mathrm{OCOCH}_{3}$ & -0.66 \\
\hline 25 & $\mathrm{NH}_{3}$ & $\mathrm{NH}_{3}$ & $\mathrm{Cl}$ & $\mathrm{Cl}$ & $\mathrm{OCOCF}_{3}$ & 0.37 \\
\hline 26 & $\mathrm{NH}_{3}$ & $\mathrm{NH}_{3}$ & $\mathrm{Cl}$ & $\mathrm{Cl}$ & $\mathrm{OCOCH}_{2} \mathrm{CH}_{3}$ & -0.25 \\
\hline 27 & $\mathrm{NH}_{3}$ & $\mathrm{NH}_{3}$ & $\mathrm{Cl}$ & $\mathrm{Cl}$ & $\mathrm{OCO}\left(\mathrm{CH}_{2}\right)_{2} \mathrm{CH}_{3}$ & 0.68 \\
\hline
\end{tabular}




\begin{tabular}{|c|c|c|c|c|c|c|c|}
\hline $28^{*}$ & $\mathrm{NH}_{3}$ & & $\mathrm{NH}_{3}$ & $\mathrm{Cl}$ & $\mathrm{Cl}$ & $\mathrm{OCO}\left(\mathrm{CH}_{2}\right)_{3} \mathrm{CH}_{3}$ & 1.72 \\
\hline 29 & $\mathrm{NH}_{3}$ & & $\mathrm{NH}_{3}$ & $\mathrm{Cl}$ & $\mathrm{Cl}$ & $\mathrm{OCO}\left(\mathrm{CH}_{2}\right)_{4} \mathrm{CH}_{3}$ & 2.94 \\
\hline 30 & $\mathrm{NH}_{3}$ & & $\mathrm{NH}_{3}$ & $\mathrm{Cl}$ & $\mathrm{Cl}$ & $\mathrm{OCO}\left(\mathrm{CH}_{2}\right)_{5} \mathrm{CH}_{3}$ & 4.22 \\
\hline 31 & $\mathrm{NH}_{3}$ & & $\mathrm{NH}_{3}$ & $\mathrm{Cl}$ & $\mathrm{Cl}$ & $\mathrm{OCO}\left(\mathrm{CH}_{2}\right)_{2} \mathrm{COOH}$ & -0.60 \\
\hline 32* & $\mathrm{NH}_{3}$ & & $\mathrm{NH}_{3}$ & \multicolumn{2}{|c|}{$\square \mathrm{OC}(\mathrm{O}) \mathrm{CH}_{2} \mathrm{O} \square$} & $\mathrm{OCOCH}_{3}$ & -0.70 \\
\hline 33 & $\mathrm{NH}_{3}$ & & $\mathrm{NH}_{3}$ & \multicolumn{2}{|c|}{$\square \mathrm{OC}(\mathrm{O}) \mathrm{CH}_{2} \mathrm{O} \square$} & $\mathrm{OCOCF}_{3}$ & -0.06 \\
\hline 34 & $\mathrm{NH}_{3}$ & & $\mathrm{NH}_{3}$ & \multicolumn{2}{|c|}{$\square \mathrm{OC}(\mathrm{O}) \mathrm{CH}_{2} \mathrm{O} \square$} & $\mathrm{OCOCH}_{2} \mathrm{CH}_{3}$ & -0.32 \\
\hline 35 & $\mathrm{NH}_{3}$ & & $\mathrm{NH}_{3}$ & \multicolumn{2}{|c|}{$\square \mathrm{OC}(\mathrm{O}) \mathrm{CH}_{2} \mathrm{O} \square$} & $\mathrm{OCO}\left(\mathrm{CH}_{2}\right)_{2} \mathrm{CH}_{3}$ & 0.40 \\
\hline 36* & $\mathrm{NH}_{3}$ & & $\mathrm{NH}_{3}$ & \multicolumn{2}{|c|}{$\square \mathrm{OC}(\mathrm{O}) \mathrm{CH}_{2} \mathrm{O} \square$} & $\mathrm{OCO}\left(\mathrm{CH}_{2}\right)_{3} \mathrm{CH}_{3}$ & 1.29 \\
\hline 37 & $\mathrm{NH}_{3}$ & & $\mathrm{NH}_{3}$ & \multicolumn{2}{|c|}{$\square \mathrm{OC}(\mathrm{O}) \mathrm{CH}_{2} \mathrm{O} \square$} & $\mathrm{OCO}\left(\mathrm{CH}_{2}\right)_{4} \mathrm{CH}_{3}$ & 2.29 \\
\hline 38 & $\mathrm{NH}_{3}$ & & $\mathrm{NH}_{3}$ & \multicolumn{2}{|c|}{$\square \mathrm{OC}(\mathrm{O}) \mathrm{CH}_{2} \mathrm{O} \square$} & $\mathrm{OCO}\left(\mathrm{CH}_{2}\right)_{5} \mathrm{CH}_{3}$ & 3.53 \\
\hline 39 & $\mathrm{NH}_{3}$ & & $\mathrm{NH}_{3}$ & \multicolumn{2}{|c|}{$\square \mathrm{OC}(\mathrm{O}) \mathrm{CH}_{2} \mathrm{O} \square$} & $\mathrm{OCO}\left(\mathrm{CH}_{2}\right)_{2} \mathrm{COOH}$ & -0.46 \\
\hline 40* & \multicolumn{3}{|c|}{ CHDA } & $\mathrm{Cl}$ & $\mathrm{Cl}$ & $\mathrm{Cl}$ & -0.16 \\
\hline 41 & \multicolumn{3}{|c|}{ CHDA } & $\mathrm{Cl}$ & $\mathrm{Cl}$ & $\mathrm{OCOCH}_{3}$ & 0.31 \\
\hline 42 & \multicolumn{3}{|c|}{ CHDA } & $\mathrm{Cl}$ & $\mathrm{Cl}$ & $\mathrm{OCOCH}_{2} \mathrm{CH}_{3}$ & 1.60 \\
\hline 43 & \multicolumn{3}{|c|}{ CHDA } & $\mathrm{Cl}$ & $\mathrm{Cl}$ & $\mathrm{OCO}\left(\mathrm{CH}_{2}\right)_{2} \mathrm{CH}_{3}$ & 1.98 \\
\hline 44* & \multicolumn{3}{|c|}{ CHDA } & $\mathrm{Cl}$ & $\mathrm{Cl}$ & $\mathrm{OCO}\left(\mathrm{CH}_{2}\right)_{3} \mathrm{CH}_{3}$ & 3.70 \\
\hline 45 & \multicolumn{3}{|c|}{ CHDA } & $\mathrm{Cl}$ & $\mathrm{Cl}$ & $\mathrm{OCO}\left(\mathrm{CH}_{2}\right)_{4} \mathrm{CH}_{3}$ & 4.26 \\
\hline 46 & \multicolumn{3}{|c|}{ CHDA } & $\mathrm{Cl}$ & $\mathrm{Cl}$ & $\mathrm{OCO}\left(\mathrm{CH}_{2}\right)_{5} \mathrm{CH}_{3}$ & 5.11 \\
\hline 47 & \multicolumn{3}{|c|}{ CHDA } & $\mathrm{OCO}\left(\mathrm{CH}_{2}\right)_{2} \mathrm{CH}_{3}$ & $\mathrm{OCO}\left(\mathrm{CH}_{2}\right)_{2} \mathrm{CH}_{3}$ & $\mathrm{OCO}\left(\mathrm{CH}_{2}\right)_{2} \mathrm{CH}_{3}$ & 3.83 \\
\hline $48^{*}$ & \multicolumn{3}{|c|}{$\mathrm{NH}_{2}\left(\mathrm{CH}_{2}\right)_{2} \mathrm{NH}_{2}$} & $\mathrm{Cl}$ & $\mathrm{Cl}$ & $\mathrm{Cl}$ & -0.83 \\
\hline 49 & \multicolumn{3}{|c|}{$\mathrm{NH}_{2}\left(\mathrm{CH}_{2}\right)_{2} \mathrm{NH}_{2}$} & $\mathrm{Cl}$ & $\mathrm{Cl}$ & $\mathrm{OCOCH}_{3}$ & -0.51 \\
\hline 50 & $\mathrm{C}_{6} \mathrm{H}_{11} \mathrm{NH}_{2}$ & & $\mathrm{NH}_{3}$ & $\mathrm{Cl}$ & $\mathrm{Cl}$ & $\mathrm{Cl}$ & 1.34 \\
\hline 51 & $\mathrm{C}_{6} \mathrm{H}_{11} \mathrm{NH}_{2}$ & & $\mathrm{NH}_{3}$ & $\mathrm{Cl}$ & $\mathrm{Cl}$ & $\mathrm{OCOCH}_{3}$ & 1.60 \\
\hline $52^{*}$ & $\mathrm{C}_{6} \mathrm{H}_{11} \mathrm{NH}_{2}$ & & $\mathrm{NH}_{3}$ & $\mathrm{Cl}$ & $\mathrm{Cl}$ & $\mathrm{OCO}\left(\mathrm{CH}_{2}\right)_{3} \mathrm{CH}_{3}$ & 4.56 \\
\hline 53 & $\mathrm{C}_{6} \mathrm{H}_{11} \mathrm{NH}_{2}$ & & $\mathrm{NH}_{3}$ & $\mathrm{Cl}$ & $\mathrm{Cl}$ & $\mathrm{OCO}\left(\mathrm{CH}_{2}\right)_{5} \mathrm{CH}_{3}$ & 6.98 \\
\hline
\end{tabular}

a The numbers marked with an asterisk are the Pt(IV) complexes in the test set; Abbreviations of the ligands are listed as follows:

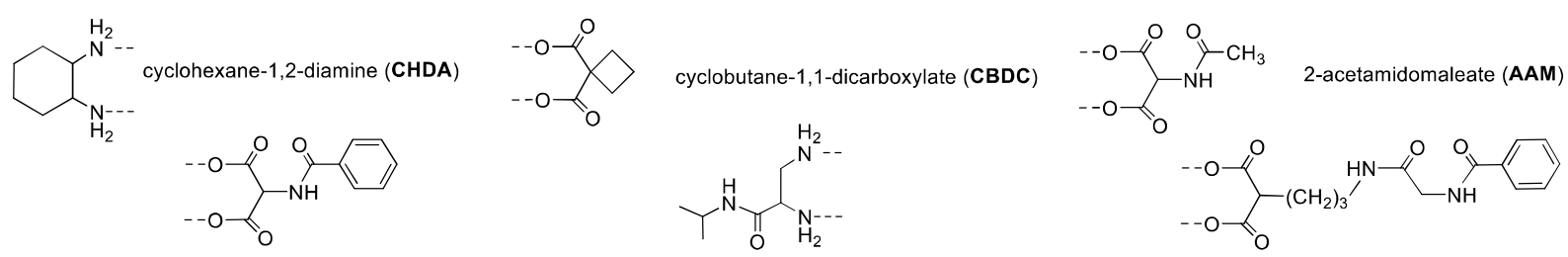

2-(benzamido)maleate (BAM)

2,3-diamino-N-isopropylpropanamide (DAPPA)

2-(3-(1-benzamido)acetamidopropyl)maleate (BAAPM) 
Table 2 Statistics of MLR, SVM, LSSVM, RF and GP models ${ }^{\text {a }}$

\begin{tabular}{|c|c|c|c|c|c|c|c|c|c|c|}
\hline & & \multicolumn{4}{|c|}{ Training set } & \multicolumn{2}{|c|}{ Test set } & \multicolumn{3}{|c|}{ MCCV } \\
\hline & & $R^{2}$ & RMSEE & $R_{C V}^{2}$ & $R M S C V$ & $R_{\text {Pred }}^{2}$ & RMSEP & $\begin{array}{l}\text { Peak } \\
R_{\text {ext }}^{2}\end{array}$ & $\begin{array}{c}\text { Median } \\
\mathrm{R}_{\mathrm{ext}}^{2}\end{array}$ & $\begin{array}{c}\text { Integral } \\
R_{\text {ext }}^{2}\end{array}$ \\
\hline \multirow{5}{*}{$\begin{array}{c}\text { PEB } \\
\text { Models }\end{array}$} & MLR & 0.87 & 0.69 & 0.81 & 0.82 & 0.77 & 0.83 & 0.88 & 0.82 & 0.79 \\
\hline & SVM & 0.88 & 0.65 & 0.84 & 0.75 & 0.56 & 1.15 & 0.64 & 0.58 & 0.56 \\
\hline & LSSVM & 0.92 & 0.52 & 0.85 & 0.74 & 0.87 & 0.62 & 0.90 & 0.86 & 0.83 \\
\hline & RF & 0.91 & 0.58 & 0.69 & 1.06 & 0.74 & 0.88 & 0.75 & 0.75 & 0.73 \\
\hline & GP & 0.94 & 0.46 & 0.83 & 0.79 & 0.84 & 0.69 & 0.89 & 0.86 & 0.84 \\
\hline \multirow{5}{*}{$\begin{array}{c}\text { AI } \\
\text { Models }\end{array}$} & MLR & 0.89 & 0.64 & 0.85 & 0.73 & 0.87 & 0.63 & 0.90 & 0.86 & 0.83 \\
\hline & SVM & 0.89 & 0.63 & 0.88 & 0.67 & 0.66 & 0.98 & 0.68 & 0.64 & 0.62 \\
\hline & LSSVM & 0.91 & 0.56 & 0.86 & 0.72 & 0.89 & 0.57 & 0.91 & 0.86 & 0.83 \\
\hline & RF & 0.89 & 0.64 & 0.61 & 1.19 & 0.86 & 0.65 & 0.70 & 0.71 & 0.70 \\
\hline & GP & 0.92 & 0.53 & 0.85 & 0.73 & 0.87 & 0.62 & 0.91 & 0.86 & 0.84 \\
\hline
\end{tabular}

a PEB Models:Pure ESP-based models; AI Models: $A_{S}$-integrated models. 
$$
\text { Conflict of Interest }
$$

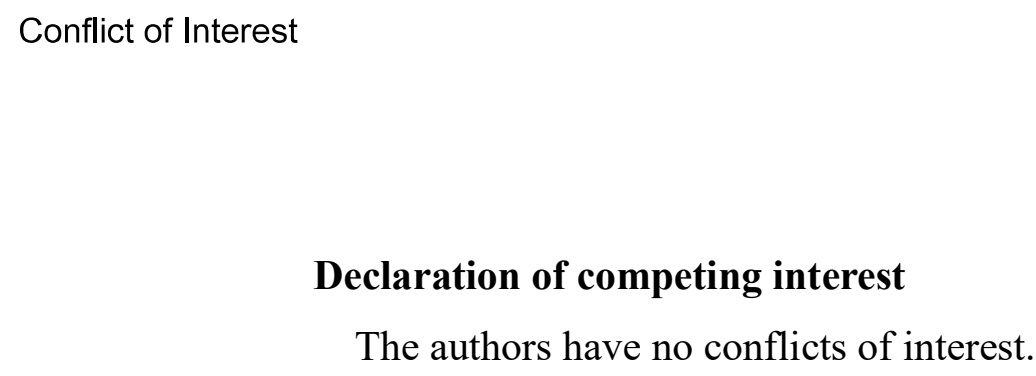

Conflict of Interest
Declaration of competing interest
The authors have no conflicts of interest.

The authors have no conflicts of interest.

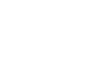

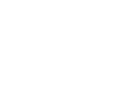

(1)
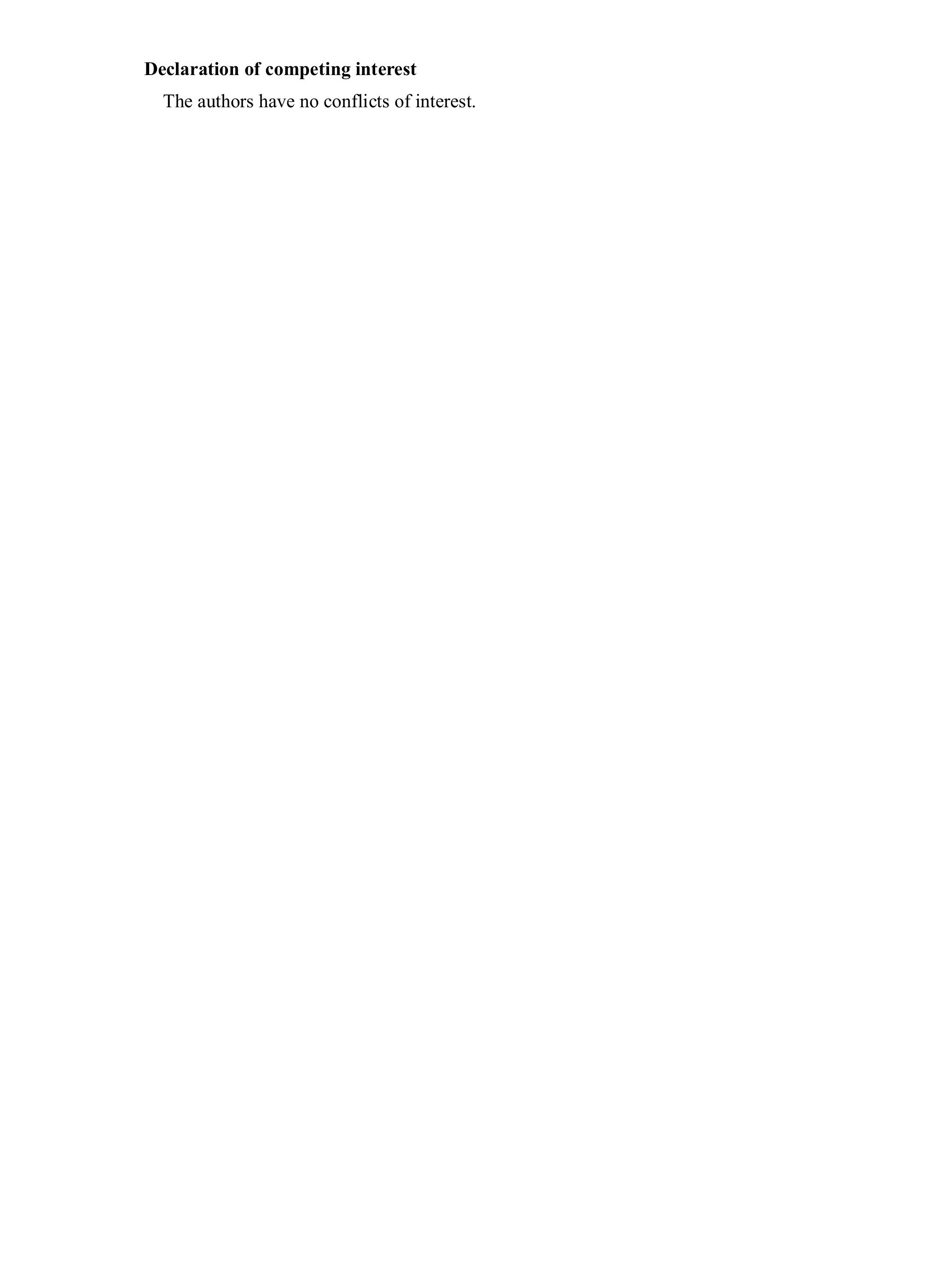


\section{CRediT author statement}

Jian-Wei Zou: Conceptualization, Methodology, Writing - Original Draft Guang-Yang Cui: Software,

Meilan Huang: Writing - Review \& Editing, Validation

Gui-Xiang Hu: Investigation

Yong-Jun Jiang: Visualization, Investigation 
Click here to access/download

Supplementary Material

Table S1-Descriptors and predicted values.docx 
Click here to access/download Supplementary Material Table S2-VIF-values.docx 
Click here to access/download

Supplementary Material

Table S3-Nonlinear models parameters.docx 
Click here to access/download Supplementary Material Table S4-Ri-values.docx 
Click here to access/download Supplementary Material logP-logk-all-122.xlsx 
Click here to access/download Supplementary Material pt_01_as_example.gjf 
Click here to access/download Supplementary Material xdesp-manual.docx 
Click here to access/download Supplementary Material Xdesp.exe 